\title{
Beiträge zur Kenntnis der Grundlagen der Fortpflanzung und zur Fruchtbarkeits- bestimmung bei marinen Teleosteern
}

\author{
Von Klaus-Jürgen Götting*) \\ Aus dem Zoologischen Institut der Universität Gießen \\ und der Biologischen Anstalt Helgoland
}

(Mit 37 Abbildungen und 12 Tabellen im Text)

\section{Inhaltsübersicht}

\begin{abstract}
A. Einleitung und Problemstellung S. 1 - B. Methodik S. 2 - C. Grundlagen der Fortpflanzung, I. Entstehung und Bau der weiblichen Keimdrüse S. 3, II. Bau der Oogonien, Oozyten und des Follikels S. 4, III. Der Ablauf der chromosomalen Reifungsvorgänge S. 13, IV. Das Verhalten von DNS und RNS während der Reifung S. 15, V. Resorption. Degeneration und Depression S. 16, VI. Zeit und Dauer des Laichens und ihre Abhängigkeit von der Verbreitung der Fischart S. 17 - D. Die Bestimmung der Fruchtbarkeit, I. Oozytenwachs'um und Fruchtbarkeitsbestimmung bei einigen Teleostcer-Arten S. 19, 1. Agonus cataphractus L. S. 20, 2. Limanda limanda (L.) S. 23, 3. Pleuronecles platessa L. S. 25, 4. Pleuronectes Resus L. S. 25, 5. Solea solea (L.) S. 26, 6. Odontogadus merlangus (L.) S. 27, 7. Engraulis encrasicholus (L.) S. 28, 8. Sprattus sprattus (L.) S. 29, 9. Cottus scorpius L. S. 31, 10. Liparis montagui Donovan S.31, II. Vergleichende Betrachtung der untersuchten Arten S. 32, III. Das Verhältnis von unreifen zu reifen Oozyten S. 33, IV. Die Regulation der Gelegegröße S. 34 - E. Die artspezifischen Beziehungen zwischen Eigröße und Größe der Olkugel S. 34 Zusammenfassung S. 37 - Angeführte Schriften S. 39.
\end{abstract}

\section{A. Einleitung und Problemstellung}

Als man vor rund achtzig Jahren anfing, sich intensiver mit den Meeresorganismen und ihrer Okologie zu beschäftigen, suchte und entwickelte man schon damals Methoden, um die Produktivität der verschiedenen Biotope an organischer Substanz quantitativ zu erfassen. Auch jetzt noch werden diese Planktonzählungen und Bonitierungsarbeiten am Sediment durchgeführt. Sie sind heute nicht mehr nur Gegenstand rein wissenschaftlichen Interesses, sondern werden mehr und mehr von praktischer Bedeutung insofern, als es darum geht, der ständig wachsenden Menschheit neue Nahrungsquellen zu erschließen.

Die Fruchtbarkeit der Teleosteer ist - obwohl man sich seit dem Ende des vorigen Jahrhunderts damit befaßt - noch keineswegs restlos geklärt. In den letzten Jahren erschienen eine Reihe von zum Teil recht ausführlichen Untersuchungen über die Eizahlen wichtiger Nutzfische, welche die Angaben älterer Autoren bestätigten oder widerlegten. Differenzen treten vor allem auf in der Bewertung des Oozytenbestandes für die Feststellung der

*) Inaugural-Dissertation zur Erlangung des Doktorgrades der NaturwissenschaftlichPhilosophischen Fakultät der Universität Gießen.

1 Meeresuntersuchungen, Bd. VIII, H. 1 
Fruchtbarkeit. Die Frage, ob die in der Größe zwischen kleinsten Oozyten und laichreifen Eiern stehenden mittleren Oozyten in der nächsten Laichzeit mit den größten zusammen abgelegt werden oder ob sie das heranreifende Gelege der übernächsten Laichperiode darstellen, ist noch immer nicht entschieden. Für eine Reihe kleinerer, nicht wirtschaftlich genutzter Fische gibt es noch gar keine Angaben der Eizahlen. Aber auch neuere Untersuchungen verschiedener Autoren an derselben Fischart (z. B. an der Kliesche) führten zu verschiedenen Ergebnissen. Hier ist also, wenn nicht eine Entscheidung getroffen werden kann, doch wenigstens weiteres Material zuzusteuern.

Es sollte und konnte nicht die Aufgabe der vorliegenden Arbeit sein, bei sämtlichen untersuchten Fischarten die Angaben über die Fruchtbarkeit statistisch zu sichern. Es kam vielmehr darauf an, das Prinzipielle der Oozytenreifung vergleichend darzustellen, um auf diesem Wege festzulegen, welcher Anteil des Gesamtbestandes an Eizellen bei der Ermittlung der Fruchtbarkeit zu berücksichtigen ist. Damit soll die Grundlage geschaffen werden für eine möglichst exakte Ermittlung der Reproduktionszahlen, für die Beseitigung jetzt noch bestehender Differenzen zwischen den Angaben verschiedener Autoren, welche dieselbe Fischart untersucht haben mit voneinander abweichenden Ergebnissen.

Die Lösung der angeführten Probleme ist das Hauptanliegen dieser Arbeit. Darüber hinaus ergeben sich noch weitere Fragen, die nach Möglichkeit geklärt werden. Nicht zuletzt war mir dic Aufgabe gestellt, die in der Literatur weitverstreuten Angaben über alles das, was mit der Fireifung ${ }^{*}$ ) zusammenhängt, zu sichten, zu ordnen und in einem kurzen Abriß übersichtlich darzustellen. Daher sind auch einige Abschnitte nach der Literatur, nicht nach eigenen Untersuchungen, abgefaf3t worden, um die Fragen der Fortpflanzung und Fruchtbarkeit der marinen Teleosteer in einen größeren Zusammenhang zu stellen.

Mein hochverehrter Lehrer, Herr Prof. Dr. W. E. Ankel, stand mir bei der Durchführung der Arbeit mit Rat und Tat zur Seite. Dafür möchte ich ihm an dieser Stelle herzlich danken. Wertvolle Anregungen erhielt ich von den Herren Prof. Dr, A. Bückmann, Hamburg, und Dr. H. J. Aurich, List. Beiden Herren möchte ich ebenso danken wie den Mitarbeitern der Biologischen Anstalt Helgoland, die mich mit Material belieferte, der Deutschen Forschungsgemeinschaft und der Gießener Hochschulgesellschaft, die finanzielle Unterstützung gewährten.

\section{B. Methodik}

Die Untersuchungen erfolgten an Ovarien, die zum größten Teil an Bord herauspräpariert und sofort fixiert wurden. Damit ergaben sich von selbst drei Gesichtspunkte für die Wahl des Fixierungsmittels:

1. es muß so gut fixieren, daß eine histologische und zytologische Bearbeitung möglich ist,

2. es muß eine nachfolgende Mazeration der bindegewebigen Bestandteile erlauben, um die Oozyten quantitativ erfassen zu können,

3. es muß einfach und möglichst ungefährlich in der Anwendung an Bord des Schiffes sein.

Diesen Anforderungen wird am besten gerecht die Fixierflüssigkeit nach Bouin, die bei der überwiegenden Mehrzahl der Ovarien verwendet worden ist. Für feinere zytologische und Kernstudien sind die Ovarstücke oder einzelne Eier nach Bouin-Allen fixiert worden.

Ein kleiner Teil des Ovars, der gewichtsmäßig auf zwei Dezimalstellen genau bestimmt wurde, lieferte das Material für die Schnitte. Die Einbettung erfolgte in Paraffin. Die Schnittdicke betrug einheitlich $0,007 \mathrm{~mm}$. Für die Färbung erwiesen sich am brauchbarsten das Hämatoxylin nach Dreafield und die Azanfärbung nad Hemennhain. Für Chromatindarstellungen wurde die Feulgensche Nuklealreaktion nach TomasI (1936) oder nach Semmens u. Bhaduri (194l) herangezogen.

Den Rest des Ovars behandelte ich mit einer Mazerierlösung. folgender Zusammensetzung:

$50 \mathrm{ml}$ Salpetersäure $(1,440)$

$20 \mathrm{~m} 1$ Eisessig

$630 \mathrm{ml}$ Wasser.

*) Mit "Eireifung" sind in dieser Arbeit alle die Vorgänge gemeint, die sich während der Entwicklung in der Oozyte abspielen und die zur Entstehung der laichreifen, befruchtungsfähigen Eizelle führen, also nicht nur Veränderungen, die die Chromosomen betreffen. 
Nach einigen Wochen bis Monaten konnten die Oozyten ausgeschüttelt werden. Eine Probe von im allgemeinen 100 Oozyten lieferte die Meßwerte für die Beurteilung der Größenzusammensetzung. Dem Rest des aufgeschwemmten Materials wurden Proben für die quantitative Auszählung entnommen, und zwar so viele, daß der Zähl und Probenfehler innerhalb der in der Praxis üblichen 5\% lag, mindestens aber fünf Proben. Das Ergebnis wurde auf die Gesamtmenge umgerechnet unter Hinzufügung des histologisch verarbeiteten und gewichtsmäBig bekannten Ovarteiles.

Um einen Uberblick über das Ausmaß der Schrumpfungen bei Fixierung und Mazeration $z u$ erhalten, habe ich einige vergleichende Messungen an einheilichem Material durchgeführt, das diesen verschiedenen Behandlungen unterworfen wurde. Die Schrumpfung erreicht maximal etwa $20 \%$, hält sich also in den üblichen Grenzen.

Für einige am Rande durchgeführte Untersuchungen wurde eine der speziellen Fragestellung angepaßte Methodik benutzt, die in dem jeweiligen Abschnitt erläutert wird.

\section{Grundlagen der Fortpflanzung}

\section{Entstehung und Bau der weiblichen Keimdrüse}

Die ersten Keimzellen sind als solche nachweisbar, wenn sie sich dorsal an den Darm angelegt haben. Von dort aus wandern sie zur späteren Gonadenregion und bilden die Genitalleiste bzw. -falte. Zunächst besteht die Genitalfalte ausschließlich aus Geschlechtszellen, später erst wandern bindegewebige Elemente ein. Die Falte schließt sich zur Röhre und bildet so Ovar und Ovidukt (Hann 1927; Anatomie der Genitalorgane bei Rauther 1954).

Nach den Untersuchungen an der Scholle werden die Genitalorgane von dorsal nach ventral verlagert. Das orale Ende des Ovars schließt sich, am caudalen Ende entsteht der Ausführgang, der nach Franz (1910) von Cölomzellen abstammen soll. Bei der Scholle tritt wie bei anderen Plattfischen auch insofern eine Besonderheit in der Anlage der Eierstöcke auf, als diese nämlich caudal die Wand der Leibeshöhle durchbrechen und einen zipfelförmigen Fortsatz bilden, der zwischen Körpermuskulatur und analen Flossenträgern liegt (Schnakenkeck 1926, Bǘckmann 1938).

Das Ovar bildet nach innen Falten, während es außen von einer ziemlich dicken bindegewebigen Hülle eingeschlossen wird, die in die Falten einwächst. Damit erlangt es seine endgültige Gestalt:

Die äußere Hülle bildet ein lockeres Bindegewebe, darunter folgt eine dünne Pigmentschicht, dann die relativ dicke Muskelschicht aus zwei Anteilen, einer äußeren zirkulären und einer inneren radiären Zone. Schließlich kommt die Bindegewebeschicht, die ihre Ausläufer in die Falten des ganz innen liegenden Keimepithels entsendet.

Die Angaben von Franz (1910) konnte ich bestätigen. Die innere Zone längsverlaufender Muskulatur ist häufig von Ringmuskulatur durchsetzt. In dieser inneren Zone finden sich Kapillaren, die auch in das Bindegewebe eindringen. Das Bindegewebe umschließt einzelne Komplexe von Oozyten, später einzelne Follikel, und damit kommen Kapillaren bis in die Theca folliculi.

Das ist das Grundschema des Aufbaus, wie es zu erkennen war an Ovarien von Pleuronectes platessa L., P. flesus L., Microstomus kitt (Walbaum), Limanda limanda (L.), Solea solea (L.), Hippoglossoides platessoides (Fabricius), Odontogadus merlangus (L.), Melanogrammus aeglefinus (L.), Gadus morrhua L., Trisopterus luscus (L.), T. minutus (O. Müller), Caranx trachurus L., Scomber scombrus L., Trigla gurnardus L., T. hirundo Bloch und Engraulis encrasicholus (L.). Die Schichtung ist aber keineswegs so einheitlich, wie es bisher 
geschildert wurde. An einer ganzen Reihe von Präparaten war festzustellen, daß das Muskelgewebe anders angeordnet sein kann. Bei einem Klieschenovar z. B. folgt auf die äußere, drei- bis vierschichtige bindegewebige Hülle zunächst die dünne Pigmentschicht, darauf eine dickere Zone längsverlaufender Muskeln, die teilweise durch bindegewebige Hüllen deutlich gebündelt sind. Dann schließt sich eine Schicht von Ringmuskulatur an, im distalen Teil noch durchsetzt von Längsmuskulatur. Radiäre Muskulatur war nicht festzustellen. Bei einem Wittlingsovar liegt zuäußerst eine Ringmuskelschicht, darauf folgen eine aus Anteilen von Längs- und Ringmuskeln gemischt zusammengesetzte und schließlich wieder eine Ringmuskelschicht. Das Ovar ist also keineswegs aufgebaut zu denken aus ineinandergeschobenen Gewebssäcken (Abb. 1), sondern

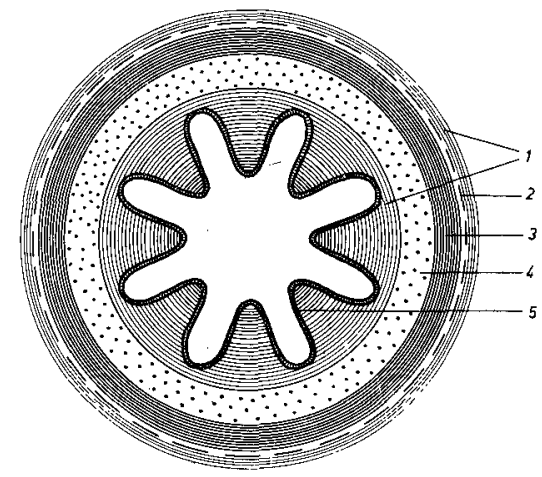

Abb. 1: Schematische Darstellung der Ovarhülle (aicht maßstabgerecht)

1. Bindegewebe, 2. Pigmentschicht, 3. Ringmuskulatur, 4. Längsmuskulatur, 5. Keimepithel

seine einzelnen Schichten sind kreuz und quer miteinander verflochten. Dadurch wird die enorme Dehnung während der Eireifung ermöglicht.

$\mathrm{Da}$, wo sie Ansatzstellen für tief in das Innere des Ovars ziehende Bindegewebsstränge bildet, kann die Ringmuskulatur radiäre Richtung annehmen. Stets ist sie dann aber umgeben von einer wirklich zirkulären Muskelschicht.

\section{Bau der Oogonien, Oozyten und des Follikels}

Der Bau der Oogonien und Oozyten in verschiedenen Stadien der Entwicklung stimmt bei den von mir untersuchten Arten mariner Fische in allen Grundzügen überein. Verschieden sind einmal die Größenverhältnisse, Dauer der Entwicklung, Zeitpunkt des Auftretens eines bestimmten Stadiums, Anordnung bzw. Vorhandensein von Dotterschollen und Ölkugeln.

Für die Reifegrade der Oozyten und die Bewertung des Reifezustandes des Ovars bei äußerer Betrachtung existiert eine Reihe von Skalen, die mehr oder weniger stark voneinander abweichen. Zur Zeit sind etwa 30 Tabellen in Gebrauch, die sich nach makroskopischen und mikroskopischen Gesichtspunkten richten. Diese Gesichtspunkte sind von NAumow (1956) zusammengestellt worden. Seit 1908 gibt es Bestrebungen, eine einheitliche Skala für alle Fischarten zu entwerfen. Die erste Skala von Heincke (1897) wurde von Maier (1908) ergänzt und auf die Scholle angewendet mit der Ansicht, daß sie auch für andere Fische Gültigkeit hätte. NAUmow übt daran und an weiteren Umarbei- 
tungen heftige Kritik. Er ist der Meinung, daß es nicht möglich ist, eine befriedigende Skala für eine ganze Familie, Gattung und sogar Art aufzustellen. Die Reifung der Gonaden bei Arten und Unterarten wäre nicht einheitlich, und das sei ,bedingt durch die Zahl schroffer biologischer Verschiedenheiten innerhalb der Art und nicht weniger innerhalb größerer taxonomischer Einheiten". Nach Darstellung meiner Ergebnisse werde ich diese Ansicht kurz diskutieren.

Die Grundtatsachen der Eireifung möchte ich zunächst beim Wittling (Odontogadus merlangus [L.]) darstellen, um dann Vergleiche zu den entsprechenden Vorgängen bei anderen Arten zu ziehen.

Die Oogonien liegen in Nestern zusammen. Auffallend ist der große, blasig erscheinende Kern. In den jüngeren Stadien ist das Chromatin noch gut darstellbar. Die aus der letzten oogonialen Teilung hervorgehenden Oozyten I. Ordnung liegen ebenfalls eng zusammen (Abb. 2 und 3). Sie wachsen zu-

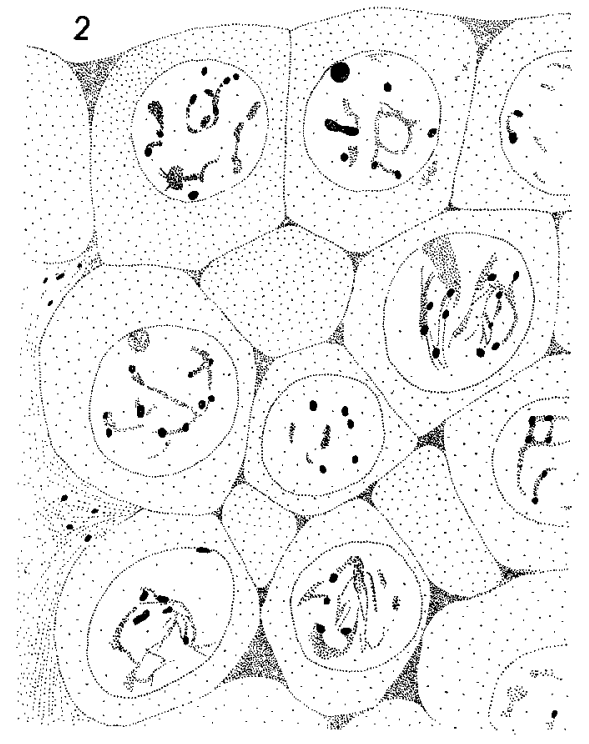

Abb. 2

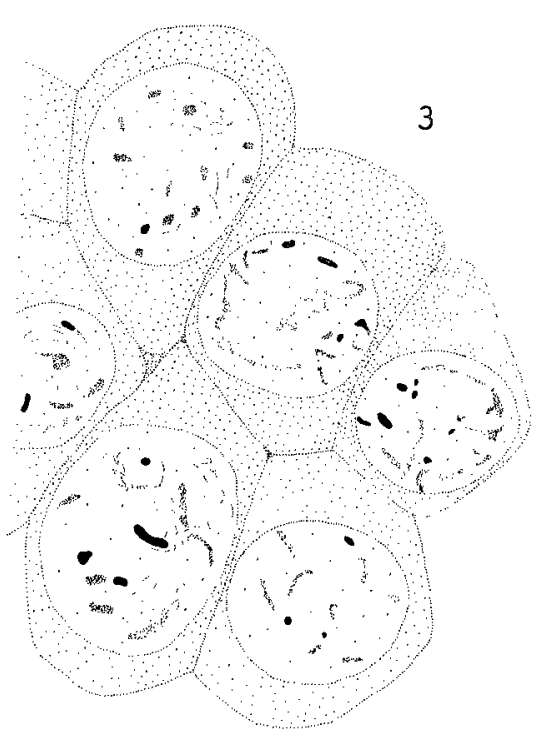

Abb. 3

Abb. 2 und 3: Oozytennester im Ovar des Wittlings

(Durchmesser des größten Kernes etwa $0,016 \mathrm{~mm}$ )

nächst (Abb. 4) und bilden einen, bald mehrere Nukleoli (Abb. 5). Diese Nukleoli wandern zur Kernperipherie. Eine (in der Literatur oft zitierte) Kernmembran im eigentlichen Sinne wird nicht ausgebildet. Schrumpft das Plasma nämlich bei der Fixierung, so zieht es sich allseitig von den Kernkörperchen zurück. Es entsteht ein regelrechter Hof um jeden einzelnen Nukleolus, besonders deutlich zu erkennen an einem Schnitt durch die Grenzregion von Karyound Zytoplasma (Abb. 6). Gäbe es eine Membran, so müßten die Nukleoli bei der Schrumpfung stets im Kernplasma liegenbleiben. Auch aus der Erscheinung, daß auf einem späteren Entwicklungsstadium, dem der intensiven Dotterbildung, der Großteil der Nukleoli in das Zytoplasma auswandert, kann man auf das Nichtvorhandensein einer Kernmembran schließen. Diese Tatsache, schon seit längerem bekannt, wurde von den älteren Autoren mit einer Auflösung der Kernmembran zu diesem Zeitpunkt erklärt. Ich nehme aus den angeführ- 
ten Gründen an, daß schon in den jüngeren Oozytenstadien keine Membran im eigentlichen Sinne vorhanden ist.

Lagen die Oozyten bisher in einem einschichtigen Follikelepithel, so wird dieses jetzt durch eine zweite Schicht ergänzt. In diesem Stadium setzen die

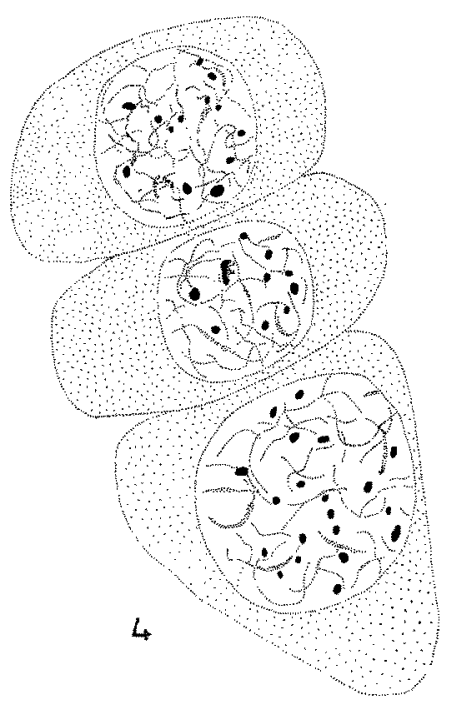

Abb. 4

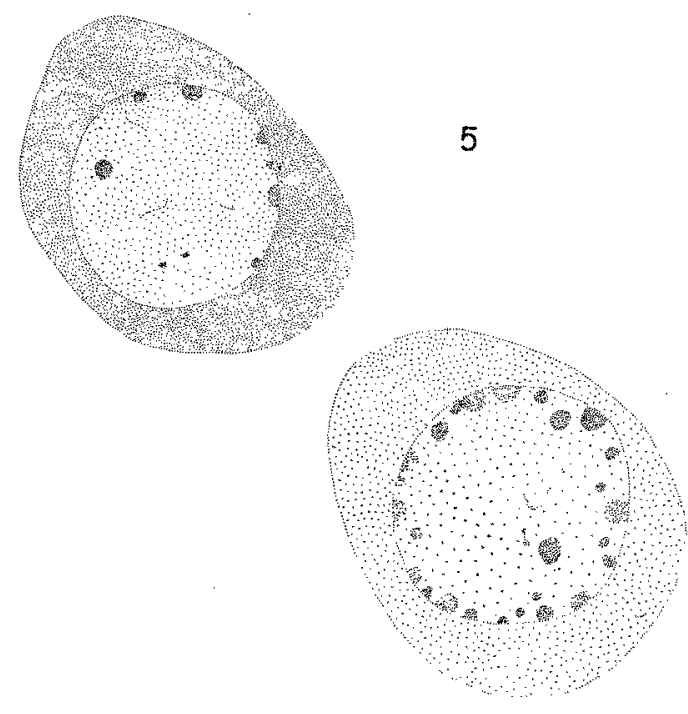

Abb. 5

Abb. 4: Junge Oozyten im Ovar des Wittlings (Durchmesser des größten Kernes 0,023 mm) Abb. 5: Auftreten der Nukleoli in den jungen Oozyten (Durchmesser der Oozyten etwa $0,07 \mathrm{~mm}$ )

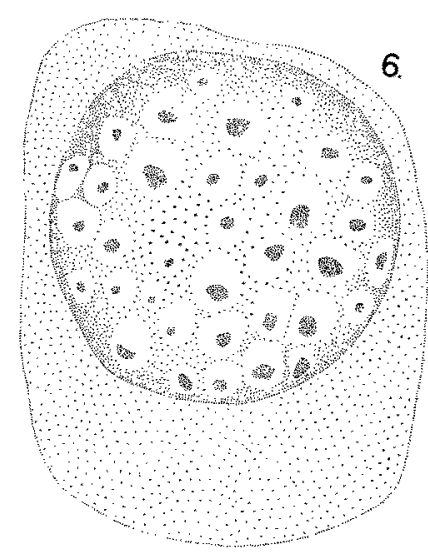

Abb. 6

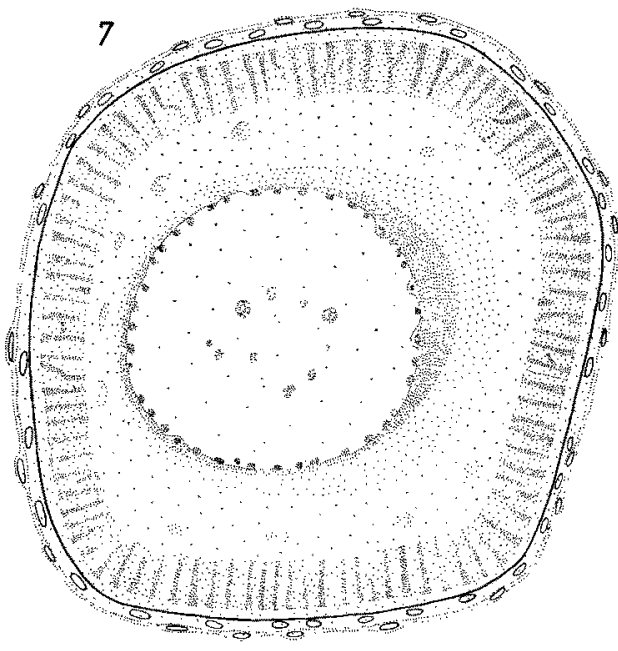

Abb. 7

Abb. 6: Nukleolenhöfe auf einem Schnitt durch die Grenzregion von Karyo- und Zytoplasma (Höhe der Oozyte $0,078 \mathrm{~mm}$ )

Abb. 7: Oozyte des Wittlings im ersten Wachstum (Breite mit Follikel 0,130 mm)

Wachstumsvorgänge ein. Sie werden offenbar unterstützt durch eine VergröBerung der Kernoberfläche, die sich wellt. Ein Teil der Nukleoli tritt bereits auf dieser frühen Phase aus dem Kernplasma heraus (Abb. 7). Das Zellplasma beginnt sich zu schichten. Auf die perinukleare Zone folgt eine homogene, dann 
eine schwächer tingierbare mit Verdichtungen und schließlich eine Schicht, in der senkrecht zur Eimembran Abschnitte gröberer mit solchen feinerer Struktur wechseln. Dadurch erscheint diese Zone radiärstreifig. Dementsprechend bezeichne ich sie als „Stratum radiatum". Nicht verwechselt werden darf sie mit der später auftretenden, ebenfalls radiär gestreiften Kortikalschicht. Nach distal schließt sich eine Schicht homogenen Plasmas an, die wahrscheinlich am Aufbau der äußeren Eihüllschichten stark beteiligt ist. Sie wird im Laufe der Entwicklung immer dünner. Den Abschluß nach außen bildet die Eimembran. Ihre innersten Schichten werden erst kurz vor Beendigung der Wachstumsvorgänge aufgelagert, wenn bereits eine Trennung in vegetativen und animalen Pol vollzogen ist. Deutlich drückt sich das im Aufbau der Hülle aus: die äußeren Schichten sind einheitlich gefärbt, sie sind hervorgegangen aus dem noch nicht polar differenzierten Plasma. Die inneren Schichten dagegen setzen sich aus zwei Anteilen zusammen: im Bereich des animalen Poles aus von diesem

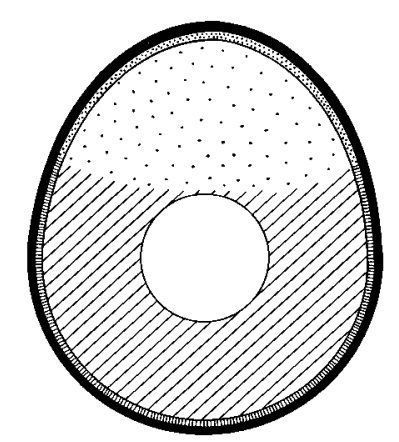

Abb. 8: S'chema des Eihüllenaufbaus aus Anteilen des undifferenzierten und des differenzierten Plasmas

schwarz: vom undifferenzierten Plasma gebildete Eihüllen, weiß: Zellkern, punktiert: vegetatives Plasma mit zugehörigen Hüllschichten, schraffiert: animales Plasma mit zugehörigen Hüllschichten

zugehörigem Plasma gelieferten Baustoffen, entsprechend liefert das vegetative Plasma die Hüllschichten am vegetativen Pol. Auf besonders gut gefärbten und differenzierten Schnitten zeichnen sich die zusammengehörigen Elemente durch die gleiche Färbung aus (Abb. 8).

Die Hüllbildung ist in letzter Zeit häufig diskutiert worden, da die älteren Arbeiten (Retzius 1912) Widerspruch fanden (Chaudhry 1956, Wickler 1957). Nach Abschluß dieser Arbeit erschien eine Veröffentlichung von ARndT (1960) über die Eihüllen von Cypriniden. Danach erfolgt auch dort die Hüllenbildung von innen her, von der Oozyte.

Im Follikelepithel sind Zellgrenzen kaum feststellbar, gut zu sehen sind dagegen die Kerne. Gleichmäßig in ihrer Dicke verläuft die innere Follikelschicht, während sich die viel dünnere äußere über ihren Kernen ausbuchtet. Im weiteren Verlaufe der Entwicklung löst sich das Stratum radiatum auf (Abb. 9). An seine Stelle tritt eine Plasmaschicht, in der sich Vakuolen bilden (Abb. 10). Diese Vakuolen entsprechen den bei Süßwasser-Teleosteern beobachteten Rindenvakuolen (Arndt 1956). Sie erfüllen schließlich etwa die Hälfte des kernfreien Raumes (Abb. 11). Zur gleichen Zeit setzt unter der Eimembran die Bildung der Kortikalschichten ein (Abb. 12). In Kernnähe tauchen die ersten Dotterelemente auf. Sie entstehen stets perinuklear. Allmählich vergrö- 


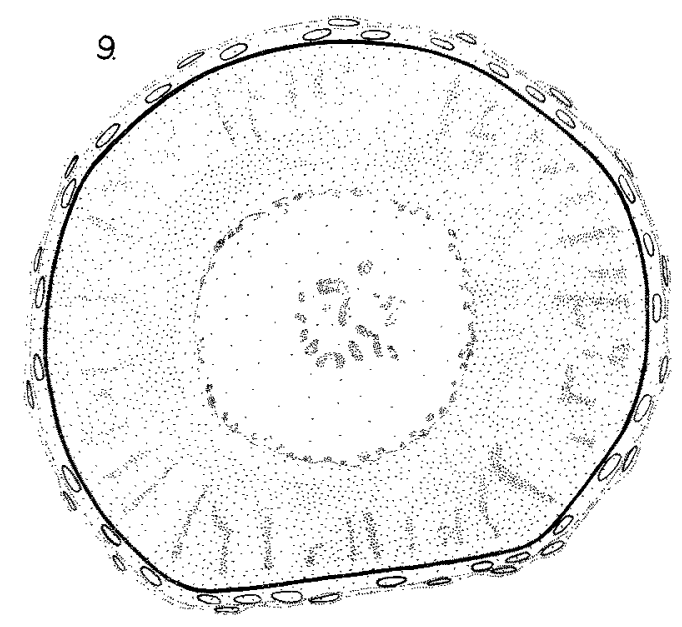

Abb. 9

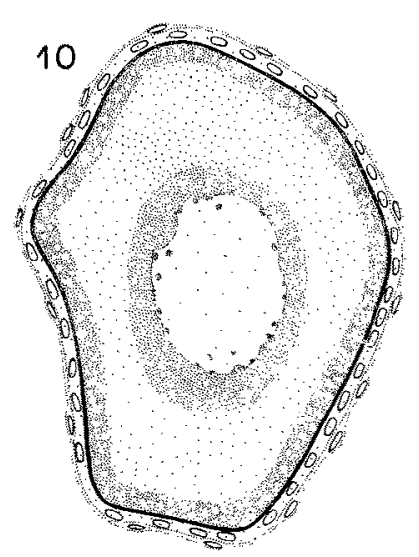

Abb. 10

Abb. 9: Auflösung des Stratum radiatum (Breite der Oozyte mit Follikel 0,157 mm) Abb. 10: Rindenvakuolen in der Oozyte des Wittlings (Höhe der Oozyte 0,281 mm)

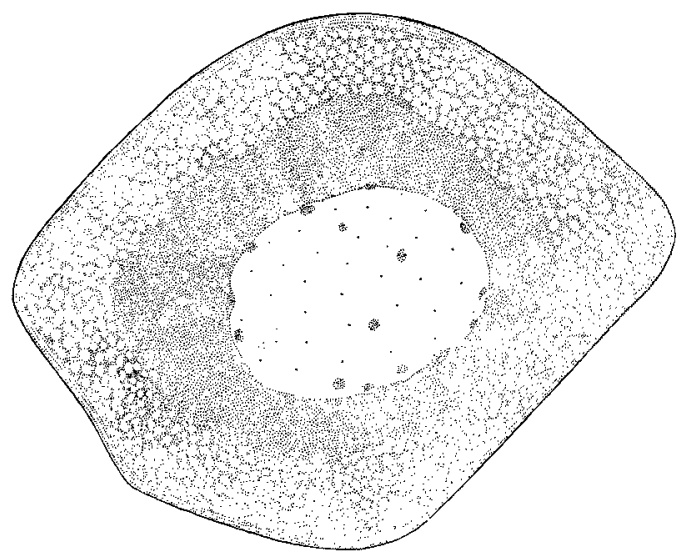

Abb. 11

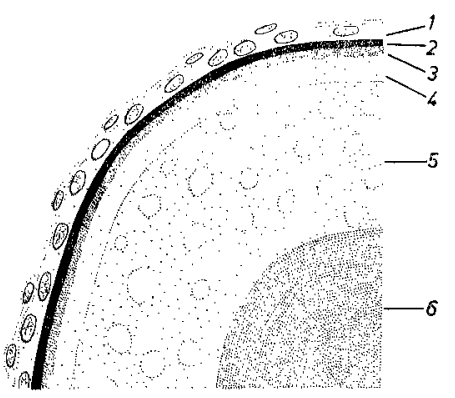

Abb. 12

Abb. 11: Vorgeschrittene Rindenvakuolenbildung (Follikel nicht gezeichnet) (Breite der Oozyte $0,290 \mathrm{~mm}$ )

Abb. 12: Stärker vergrößerter Ausschnitt aus den peripheren Schichten einer Oozyte. Bildung der ersten Rindenschicht (Breite des Ausschnittes 0,06 mm)

1. zweischichtiger Follikel, 2. primäre Oozytenmembran, 3. erste Kortikalschicht, 4. Zone hyalinen Plasmas, 5. Plasmaschicht mit Vakuolen, 6. perinukleares Plasma

Bert sich ihre Zahl, sie erfüllen mehr und mehr Raum und verdrängen die Rindenvakuolen, die völlig aufgelöst werden (Abb. 13).

Die Kortikalschicht verdickt sich. Durch die Anordnung ihrer Teilchen senkrecht zur primären Oozytenmembran erhält sie ein bei oberflächlicher Betrachtung radiärstreifiges, in Wirklichkeit aber ein gekreuztes Muster (Abb. 14), da senkrecht zu den Radiärstreifen, also parallel zur Eimembran, sich die Schichtung der Hülle bemerkbar macht. Die Radiärstreifung läuft durch die Cortex glatt durch, gleichgültig, wieviele Schichten diese aufbauen. Die Streifung wird durch besondere Brechungsverhältnisse bedingt, es scheint sich nicht um Porenkanälchen zu handeln (Sterba und Franke 1959). 
Es ist jetzt notwendig, den Begriff des Stratum radiatum genauer abzugrenzen. Als Stratum radiatum bezeichne ich die oben beschriebene Plasmaschicht, die nur auf einem vorübergehenden Entwicklungsstadium auftritt und an deren Stelle sich später die Schicht der Rindenvakuolen bildet. Das Stratum radiatum scheint typisch zu sein für die Oozyten der Gadiden. Bei anderen Fischen konnte ich es nicht beobachten. Demgegenüber nenne ich die einschichtige, radiärstreifig erscheinende Rindenschicht Cortex radiata. Durch die Auflagerung mehrerer Schichten erhält sie kreuzstreifiges Aussehen.

Eine sehr ähnliche Bildung, in der Literatur als Zona radiata oder Corona radiata (STöнr 1919) bezeichnet, soll bei Esox lucius L. auftreten (KraUse 1921). Die Zona radiata des Hechtes ist angeblich vom Follikelepithel gebildet
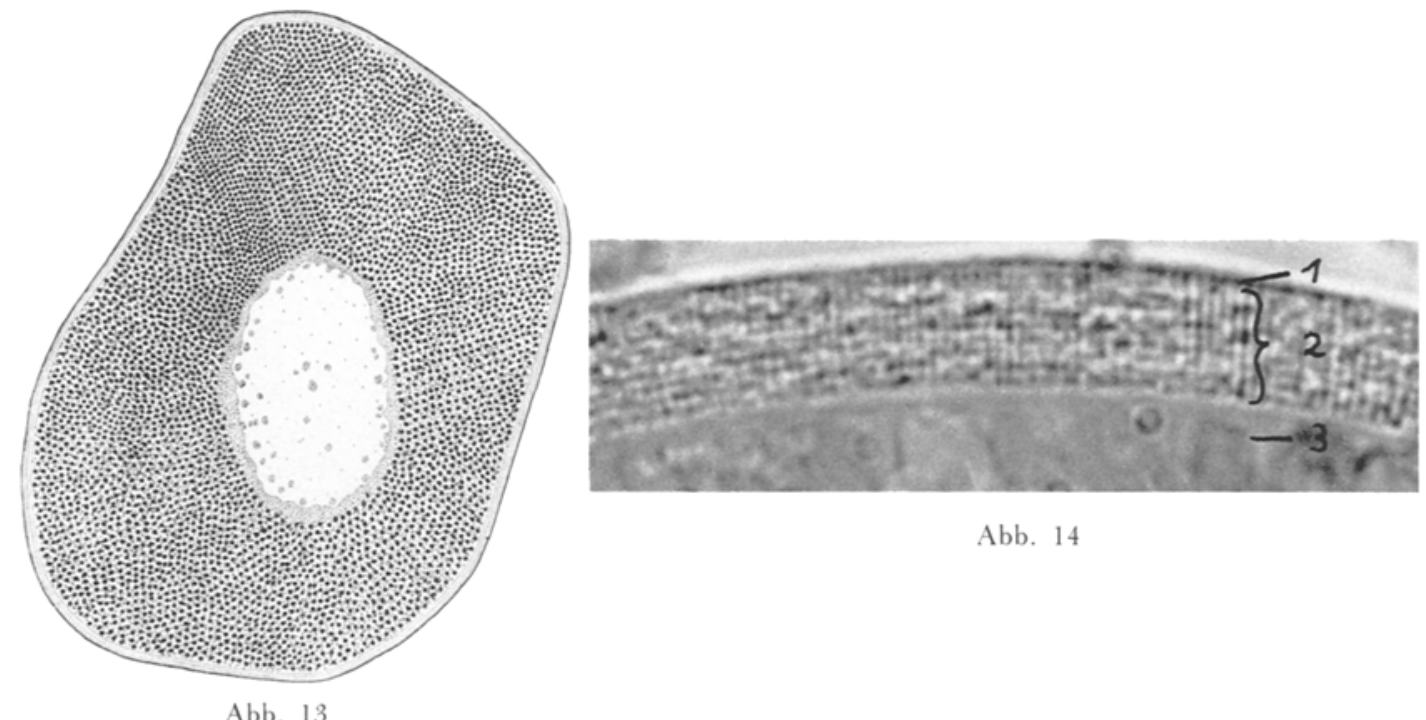

Abb. 14

Abb. 13: Dottererfüllte Oozyte des Wittlings (Höhe der Oozyte 0,395 mm)

Abb. 14: Schnitt durch die Kortikalschichten (Dicke der Rinde 0,013 mm)

1. Oozytenmembran, 2. Kortikalschichten, 3: Zytoplasma

worden. Es drängt sich aber der Verdacht auf, daß diese Struktur identisch ist mit der Cortex radiata, bei der es sich nach meinen Beobachtungen um ein Produkt des Eizellplasmas handelt. Die Schichtbildung erfolgt nämlich 1. innerhalb der Oozytenmembran und 2. immer von innen her, wie die unterschiedliche Färbbarkeit der von bereits polar differenziertem Plasma gebildeten Rindenschichten beweist. Zum gleichen Ergebnis gelangen STERBA (1957) bei Melanotaenia maccullochi und Arndt (1960) bei verschiedenen Cypriniden. Bei Naumow (1956) ist der Begriff „Zona radiata" ganz eindeutig nicht im Sinne der Definition gebraucht. Er bezeichnet damit die von mir Cortex radiata genannte Struktur in der Oozytenrinde des Herings (Clupea harengus harengus L.). Die Zona radiata ist definiert für die Mammalia als innerste Schicht des Follikelepithels, dessen Zellen sich in charakteristischer Weise radiär um das Ei herum anordnen. Eine echte, also vom Follikelepithel gebildete, Zona radiata war bisher bei Teleosteern nicht nachzuweisen.

Bei der weiteren Entwicklung der Oozyte kommt es zu Verschmelzungen der Dotterkörner. Gleichzeitig verläßt der Kern seinen Platz im Zentrum und wandert zur Peripherie. Damit verliert die Eizelle ihren konzentrischen Bau. 
Das Plasma differenziert sich in einen animalen Anteil in Kernnähe und in einen vegetativen, der den Dotter enthält. Damit sind die wichtigsten Entwicklungsvorgänge abgeschlossen.

Wie bei allen Anamnia, Sauropsida und aplacentalen Mammalia ist der Follikel der Fische ein Folliculus solidus (Bretschneider und Duyvené de WIT 1947). Er besteht aus mehreren Schichten, die sich aus Anteilen des Keimepithels und des Bindegewebes entwickeln.

Während die künftigen Eizellen sich bald durch ihren Reichtum an Zytoplasma, ihren kugeligen Kern und hohen Gehalt an Chromatin von ihrer Umgebung abheben, entstehen neben ihnen andere Zellen, die über relativ wenig Chromatin verfügen und durch den Druck der benachbarten Zellen

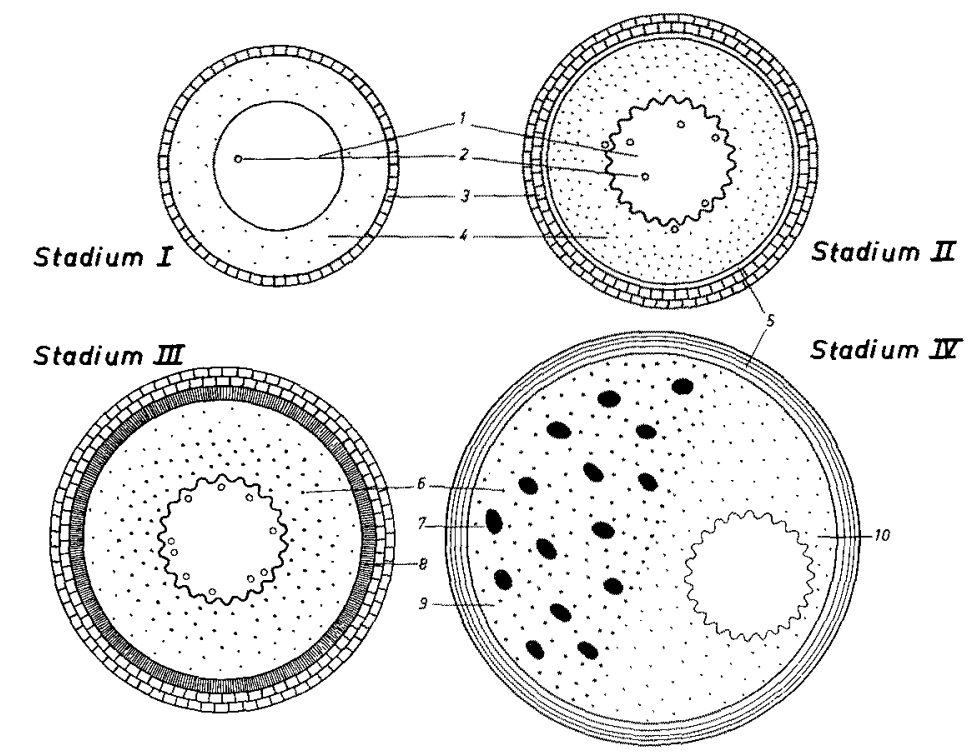

Abb. 15: Schema der Entwicklungsstadien der Oozyte

1. Kern, 2. Nukleolus, 3. Follikel, 4. Plasma, 5. Kortikalschichten, 6. Dotterkörner, 7. Dotterschollen, 8. Cortex radiata, 9. vegetativer Pol 10. animaler Pol

abgeflacht werden. Sie gruppieren sich um die Keimzellen und bilden später die Membrana granulosa des Follikels. Während in der Oozyte die Entwicklung zum reifen $\mathrm{Ei}$ abläuft, schließen sich die Granulosa-Zellen um das Ei zusammen. Von der nächstgelegenen bindegewebigen Wand lösen sich einige Fibroblasten und wandern auf die Granulosa, so die Theca folliculi bildend.

An der Bildung der Eihüllen ist der Follikel nicht direkt beteiligt. Er bleibt erhalten bis zum Eintritt der Laichperiode. Durch die starke Vergrößerung des Eies wird er gedehnt und schließlich gesprengt. Das Ei gelangt zunächst in die Ovarialhöhle und dann durch den Ovidukt nach außen.

Nach histologischen Gesichtspunkten möchte ich nun eine Einteilung in Stadien vornehmen, wobei ich mich im wesentlichen ArNDT anschließe (Abb. 15).

Stadium I:

Oozyte konzentrisch gebaut, Kern relativ groß und bläschenförmig, sein Umriß also rund. Zytoplasma basophil, ebenso die in Ein- oder Mehrzahl vorhandenen Nukleoli. Follikel einschichtig. 
Stadium II:

Vergrößerung der Kernoberfläche durch Wellung. Einige Nukleoli treten in das Zytoplasma über. Beginn der Plasmaschichtung. Etwas später entstehen Rindenvakuolen. Die Bildung der Kortikalschichten beginnt. Follikel zweischichtig.

Stadium III:

Die Dotterbildung setzt ein. Die Rindenvakuolen werden verdrängt und verschwinden. Die Cortex radiata tritt in Erscheinung.

Stadium IV:

Die Dotterkörner verschmelzen mehr oder weniger stark. Der Kern verläßt das Eizentrum. Das Plasma differenziert sich polar. Die Oozyte hat damit den konzentrischen Aufbau verloren,

Diese Einteilung gilt für alle von mir untersuchten Teleosteer, aber auch für Süßwasserfische wie Coltus bairdii (HANN 1927), Cyprinus carpio, Leuciscus rutilus (ARNDT 1956) und Melanotaenia maccullochi (STERBA 1957). Es ist also wohl das Grundschema der Oozytenentwicklung der Teleosteer überhaupt. Allerdings ist die Einteilung grob. Sie läßt sich aber nur verfeinern im Bereich der Art. Wir werden weiter unten sehen, daß die Oozytenentwicklung bei verschiedenen Spezies oft charakteristische Abwandlungen zeigt. In diesem Sinne

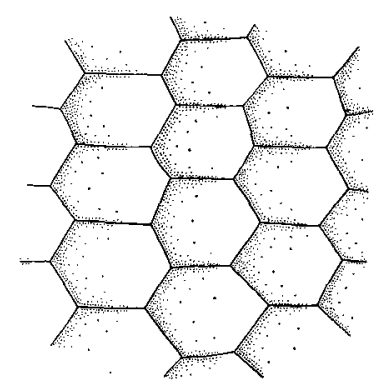

Abb. 16: Oberflächenstruktur der Oozyten von Callionymus lyra (größte Breite einer Wabe $0,011 \mathrm{~mm})$
Abb. 17: Schnitt durch cine Oozyte von Callionymus lyra mit Eihautleisten Höhe der Oozyte $0,285 \mathrm{~mm}$ )

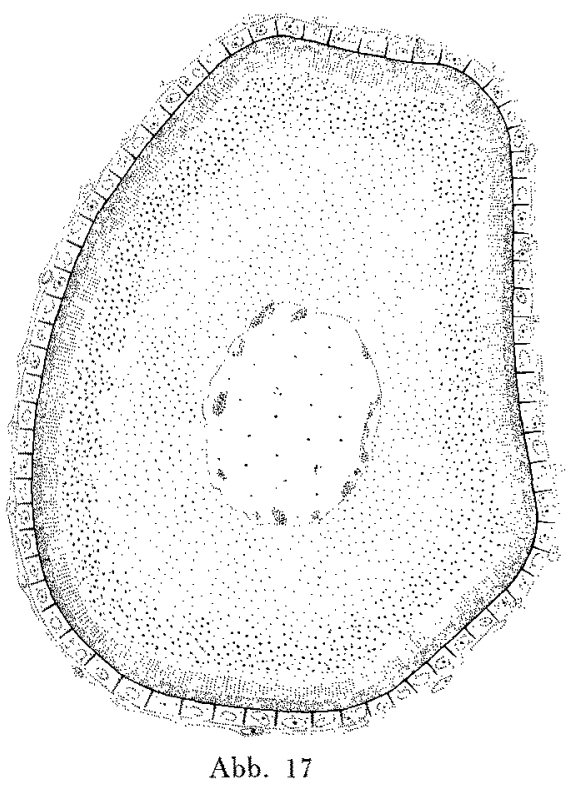

hat Naumow recht mit seiner Kritik an Reifeskalen, die für größere taxonomische Einheiten gelten sollen. Das tut allerdings ihrer Brauchbarkeit für Untersuchungen von industriell-kommerzieller Zweckgebundenheit keinen Abbruch.

Wie beim Wittling liegen die Verhältnisse bei einer Reihe anderer Fische mit planktischen Eiern: Melanogrammus aeglefinus (L.), Gadus esmarki Nilss., Trisopterus luscus (L.) und T. minutus (O. Müller). Beim Dorsch (Gadus morrhua L.) ist die perinukleare Plasmaschicht (im Stadium II) besonders ausgeprägt und kräftig färbbar. Die Rindenschichten der Oozyten von Trigla gurnardus L. und $\mathcal{T}$. hirundo Bloch sind etwas dicker als die der Gadiden. Bei 
Scomber scombrus L., Caranx trachurus L., Sprattus sprattus (L.) und Engraulis encrasicholus L. waren keine wesentlichen Unterschiede festzustellen.

Die Eier von Callionymus lyra L. sind ausgezeichnet durch eine wabenförmige Oberflächenstruktur. Diese Struktur wird auf der Oozytenmembran schon frühzeitig angelegt. Die ersten Erhebungen sind am Ende von Stadium I sichtbar. Das Wabenmuster ist nicht ganz regelmäßig sechseckig (Abb. 16). Die Zellen der inneren Follikelschicht sind in die Fächer hineingedrückt (Abb. 17), während sich die der äußeren über die Leisten hinwegziehen.

Sehr auffällig sind die Auflösungserscheinungen der Nukleoli von Callionymus lyra. Im Gegensatz zu den Kernkörperchen der übrigen Teleosteer
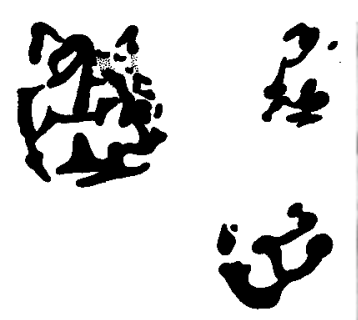

Abb, 18: Auflösungscrscheinungen an den Nukleoli von Callionymus lyra (Durchmesser des größten Nukleolus $0,02 \mathrm{~mm})$

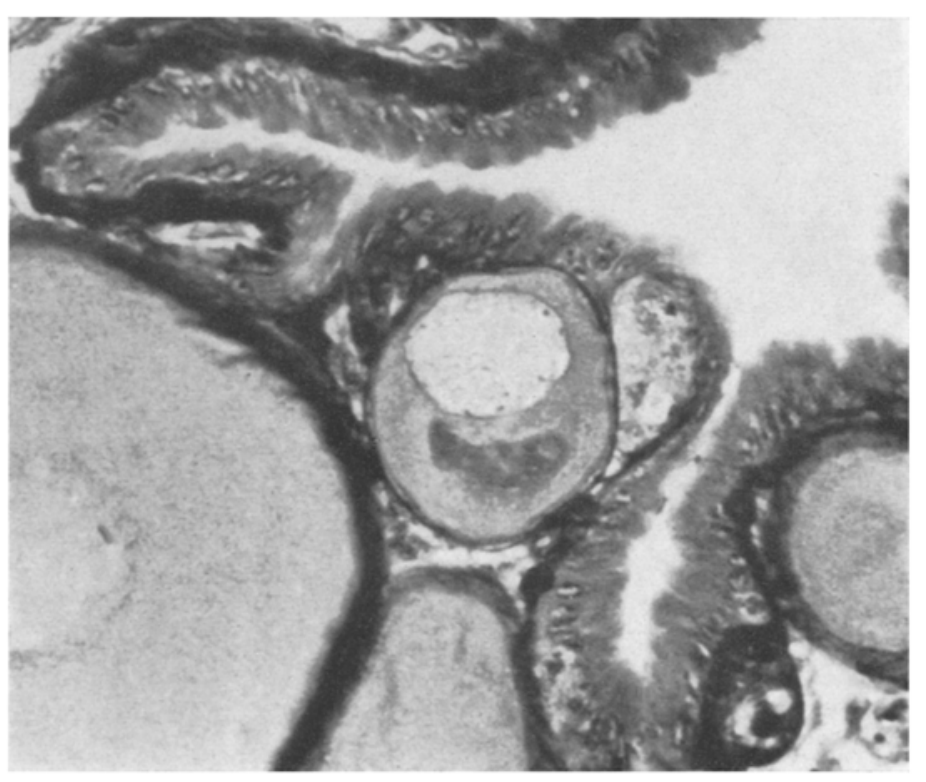

Abb. 19

Abb. 19: Oozyte von Agonus cataphractus mit chromatischen Bezirken im Zytoplasma (Durchmesser der Oozyte $0,08 \mathrm{~mm}$ )

sind die des Leierfisches enorm groß. Wahrscheinlich sind sie so groß, daß es ihnen nicht möglich ist, die Grenzschicht zwischen Karyo- und Zytoplasma zu durchbrechen. Die Auflösung ist nämlich keineswegs ein Ausnahmefall, sondern die Regel (Abb. 18). Das Trägheitsmoment der kleinen Bruchstücke und ihr mechanischer Widerstand beim Transport sind geringer, ihre wirksame Oberfläche ist größer - das dürften die Gründe sein, die zur Auflösung führen.

Der gegensätzliche Extremfall tritt in den Oozyten von Agonus cataphractus auf. Chromatische Kernsubstanz verläßt hier den Nukleus in fein verteilter Form und durchsetzt die perinukleare Plasmaschicht. Bei der weiteren Entwicklung löst sich diese Schicht auf. Ihre Reste bleiben noch einige Zeit in Form wolkig aussehender Bezirke erhalten und verschwinden allmählich (Abb. 19).

Die Eihüllen von Agonus cataphractus und Cottus scorpius L. sind bedeutend dicker als die der bisher erwähnten Fische. Das hängt sicher damit zusammen, daß beide Arten keine planktischen, sondern festsitzende Eier legen. 
Die Verhältnisse bei den Plattfischen Pleuronectes platessa, P. flesus, Microstomus kitt, Hippoglossoides platessoides, Limanda limanda und Solea solea unterscheiden sich nicht von denen bei anderen Fischen mit planktischen Eiern.

\section{Der Ablauf der chromosomalen Reifungsvorgänge}

Am Beispiel des Wittlings möchte ich die Veränderungen besprechen, die die Chromosomen während der Reifungsvorgänge durchmachen.

Die Oogonien teilen sich mehrmals. Aus der letzten Teilung geht die Oozyte I. Ordnung hervor. Sie ist zunächst im Stadium I und macht die erste

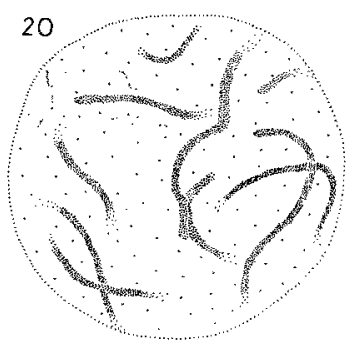

Abb. 20

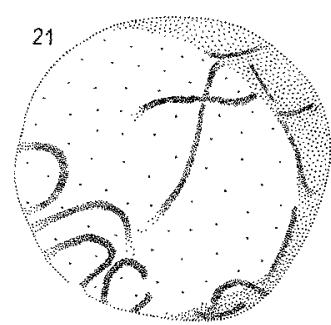

Abb. 21

Abb. 20: Leptotän (Durchmesser des Kernes etwa 0,007 mm) Abb. 21: Spätes Bukett. Beginn der synaptischen Verschmelzung (Durchmesser des Kernes etwa $0,007 \mathrm{~mm}$ )

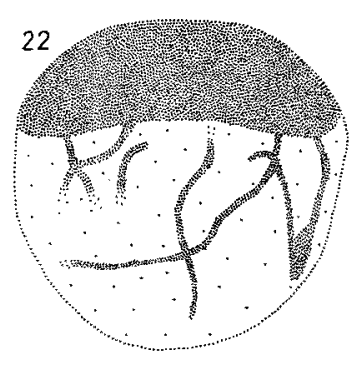

Abb. 22

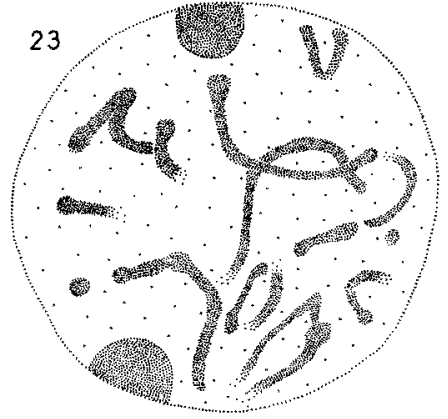

Abb. 23

Abb. 22: Leptotän kurz vor dem Höhepunkt der Synapse (Durchmesser des Kernes etwa $0,008 \mathrm{~mm}$ )

Abb. 23: Pachytän (Durchmesser des Kernes etwa 0,013 mm)

Wachstumsphase durch, wobei sie nur um ein geringes größer wird. Der wesentliche Vorgang besteht in der Vorbereitung der Chromosomen für die 1. Reifungsteilung.

Das Leptotän (Abb. 20) scheint nur von sehr kurzer Dauer zu sein. Die Chromosomen orientieren sich polar zu „Bukettstadien“ (Abb. 21) und damit beginnt die Konjugation. Charakteristisch für die Stadien der Konjugation ist eine Fixierungslabilität, die zur „synaptischen Verklumpung“ führt. Dabei verschmelzen die freien Bukettchromosomen in ihrem Berührungspunkt. Das Chromatin zieht sich zu einer halbmondförmigen Figur an der Kernmembran zusammen, aus der die Enden der Chromosomen zunächst noch herausragen 


\section{$r$}

sit

Abb. 24: Bildung des ersten Richtungskörpers nach der 1. Reifungsteilung (Breite des gezeichneten Ausschnittes etwa 0,070 mm)

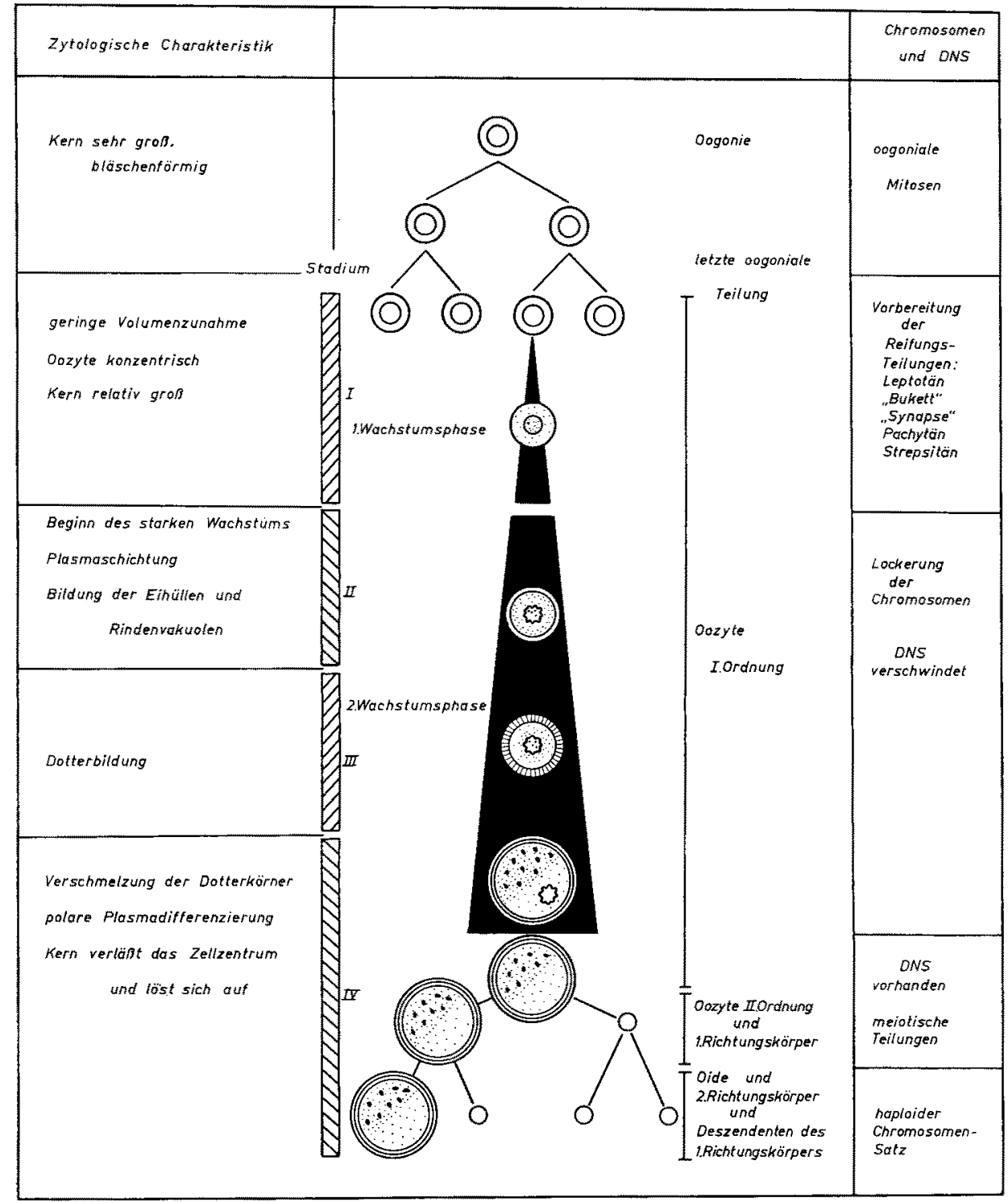

Abb. 25: Übersicht über den Zusammenhang der Entwicklungsstadien von Zytoplasma und Chromosomen in den Oozyten 
(Abb. 22). Auf dem Höhepunkt der „Synapse“ sind sie zu einem einheitlichen Klumpen verschmolzen. Die Synapse wird heute als Artefakt aufgefaßt, dessen Entstehung durch eine besonders hohe Empfindlichkeit der Chromosomen während der Konjugationsphase gegenüber Fixiermitteln ursächlich bedingt ist (BĔLAR̆ 1928).

Durch die Synapse entziehen sich das Zygotän und der Beginn des Pachytän der Beobachtung. Erst im Verlaufe des Pachytän löst sich die Verklumpung und die Einzelchromosomen werden sichtbar (Abb. 23). Gegen Ende der ersten Wachstumsphase lockern sie sich zum Strepsitän.

Beim Übergang zur 2. Wachstumsphase wird die Despiralisation soweit fortgesetzt, daß die Chromosomen schließlich ganz verschwinden. Sie sind durch die Feulgensche Nuklealreaktion nicht mehr nachzuweisen. Offenbar verharren sie in einem Ruhestadium bis die zytoplasmatischen Reifungsvorgänge in der Oozyte abgeschlossen sind. Diese durchläuft dabei die im II. Abschnitt dargestellten Stadien II und III. Kurz vor der ersten Reifungsteilung (Abb. 24) ist Stadium IV erreicht. Die Chromosomen werden sichtbar und bereiten sich auf die meiotischen Teilungen vor. Die Oozyte II. Ordnung, die Oide (Ankel 1933) und schließlich das befruchtungsfähige Ei gehören zu Stadium IV. Die Zuordnung der einzelnen Stadien der zytologischen und chromosomalen Entwicklung ist dem Schema (Abb. 25) zu entnehmen.

\section{Das Verhalten der DNS und RNS während der Reifung}

Ähnlich wie bei anderen Tiergruppen ist die Darstellbarkeit der Desoxyribonucleinsäure (DNS) während des Ablaufes der Reifungsvorgänge Schwankungen unterworfen.

In den Oogonien ist sie verhältnismäßig gut darstellbar. Schon in den jüngeren Oozyten entzieht sie sich jedoch den bisher für Kernfärbungen angewandten Methoden. Sie bleibt unsichtbar während der Reifungsvorgänge in den Oozyten und taucht erst im reifen $\mathrm{Ei}$ wieder auf.

Von den bisher untersuchten Teleosteern macht die Karausche (Carassius carassius [L.]) insofern eine Ausnahme, als die DNS auch zutage tritt in den Kernen junger Oozyten, die noch nicht in die Phase des starken Wachstums eingetreten sind (Petrowa 1956). Erst wenn die Oozyten ein mittleres Volumen von $200 \cdot 10^{3} \mu^{3}$ erreicht haben, gibt der Kern keine positive Feulgenreaktion mehr.

Diese Darstellung muß ich nach den Befunden an den von mir untersuchten marinen Teleosteern dahingehend erweitern, daß off enbar bei sorgfältiger Fixierung und Färbung das Chromatin während der ersten Wachstumsphase durchaus sichtbar bleibt. Es verschwindet erst mit Beginn der 2. Wachstumsphase.

Parallel mit dem Verschwinden der DNS im Kern läuft die Bildung neuer Kernkörperchen, in denen RNS angereichert ist. Die Größe der Nukleoli ist verschieden.

Sobald die Oozyte I. Ordnung mit der Vorbereitung der ersten Reifungsteilung beginnt, wandert der Kern mehr an die Peripherie der Zelle. In diesem Stadium sammeln sich die noch vorhandenen Nukleoli in der Mitte des Kernes und verschmelzen zum Teil miteinander. Franz (1910) konnte nachweisen, daß die großen Nukleoli den Kern verlassen und dann das bilden, was von älteren 
Autoren als "Centrosom", von anderen als "Dotterkern" bezeichnet wurde, von dem aus die Bildung des Dotters einsetzen soll. Auf diese Ansicht greift eine neuere Arbeit von StERba (1957) zurück, der an Melanotaenia maccullo$d i$ in jungen Oozyten einen gut abgegrenzten Dotterkern beobachtete. Dieser schnürt später Nebenkerne ab. Seine Grundsubstanz ist grobwabig angeordnet, die dicken Wabenwände schließen sehr feine Granula ein. Sterba ist der Meinung, daß in diesen wabigen Strukturen der Entstehungsort der Dotterschollen und Fettvakuolen zu sehen ist. Dem steht die Tatsache gegenüber, daß Dotter in den Oozyten bereits vorhanden ist, ohne daß ein Dotterkern festzustellen wäre.

Bei allen untersuchten Arten konnte ich feststellen, daß die Nukleoli den Kern verlassen können. Darauf habe ich schon bei der Schilderung der Oozytenentwicklung hingewiesen. Auch die Auflösungserscheinungen der Nukleoli bei Callionymus lyra habe ich dort besprochen. Vielleicht sind die Gebiete wolkigen Aussehens in den Oozyten von Agonus cataphractus identisch mit den erwähnten Dotterkernen. Der Name „Dotterkern“ ist auf alle Fälle irreführend, da diese Bildung nicht Voraussetzung für das Entstehen von Dotter ist.

Es dürte wohl so sein, daß die Nukleoli dadurch, daß sie den Kern verlassen, die Menge an RNS im Zytoplasma erhöhen. Die RNS fungiert als Energieüberträger, ohne aber den eigentlichen Anstoß zur Dotterbildung zu geben, die davon unabhängig einsetzt oder bereits eingesetzt hat. Es ist nämlich auffallend, wie stark die Färbbarkeit des Zellplasmas schwankt. Solange das schnelle Wachstum in der Oozyte noch nicht eingesetzt hat, erhält man eine intensive Reaktion auf RNS (Methylgrün-Pyronin). Mit dem Beginn des Wachstums und dem Auftreten der Dotterkörner nimmt die Intensität der Reaktion schnell ab.

Entsprechende Erscheinungen sind auch von anderen Tierarten bekannt, zum Beispiel von Insekten (Schrader 1951) und Nematoden (Wessing 1954). Eine Übersicht über das DNS-RNS-System gibt Lorenzen (1960). Danach läuft die Proteinsynthese im Zytoplasma unter Beteiligung von RNS ab, deren Synthese wiederum abhängig ist vom Vorhandensein des Kernes. Ein vereinfachtes Bezichungsschema stammt von Brachet (1960), in Wirklichkeit dürften die Verhältnisse der wechselseitigen Einwirkungen sehr kompliziert sein.

\section{Resorption, Degeneration und Depression}

In jedem Ovar laufen bestimmte Vorgänge ab, die zum Teil einmalig, zum Teil periodisch wiederkehrend auftreten.

$\mathrm{Zu}$ letzteren gehört nach jeder Laichzeit die Resorption leerer Follikel. In der Granulosa und in der Theca folliculi interna verschwinden die Zellgrenzen, ebenso das Chromatin der Kerne. Die Theca folliculi externa bleibt zunächst als solche erhalten und schließt den ehemaligen Follikel ein, der schließlich zu einem soliden Gewebe wird.

Nicht selten bleiben nach dem Ablaichen einige reife Eier im Ovar zurück. Sie werden bald weißlich trübe. Nhnlich sehen Eier aus, die schon zu einem früheren Zeitpunkt der Entwicklung anfangen zu degenerieren. Wodurch diese Degenerationsprozesse ausgelöst werden, ist nicht bekannt. BRETSCHNEYDer und Duyvené DE WIT (1947) fassen die Degenerate als Corpus luteum auf, weil sie eine hormonale Wirkung vermuten. 
Nach Franz führt der Abbau fast reifer Eier zu einer Depression des Ovars. Die Degeneration soll einsetzen, wenn Oozyten in ihrer Entwicklung bis zur Phase der intensiven Dotterbildung gelangt sind und dann nicht die notwendige weitere Stoffzufuhr eintritt (vgl. auch Cunningham 1898).

Dazu ist zu bemerken, daß bei den von mir untersuchten Ovarien ein Großteil der Oozyten durchaus längere Zeit auf diesem kritischen Stadium zu verharren scheint, ohne daß eine Degeneration beginnt, die das Ovar ja auch unnötig belasten würde, weil Tausende von Oozyten abgebaut werden müßten. Einen ähnlichen Gedanken hatte Franz vielleicht, wenn er meint, daß die im Depressionszustande befindlichen Eier eine Lähmung der Oozytenbildung bewirken und eine erhebliche Verlangsamung des Stoff wechsels. Es wäre denkbar, daß einige Eier geopfert werden, um vielleicht auf hormonalem Wege die Entwicklung der großen Masse der Eizellen zu lenken. Bemerkenswert ist, daß das Vorhandensein relativ weitentwickelter Eier, die nicht abgelegt werden, zu einer Blockierung der gesamten Gonade führen kann. Damit wird eventuell eine Unfruchtbarkeit hervorgerufen, die sich über die nächste Laichzeit erstreckt, ja im Extremfall lebenslänglich ist (BARFurT 1886). Nach der Feststellung von BretschneIder und Duyvené de WIT (1937) sind Eiabbauprozesse eine periodische, normale Erscheinung in der autonomen Tätigkeit der Gonade.

VI. Zeit und Dauer des Laichens und ihre Abhängigkeit von der Verbreitung der Fischart

Es ist grundsätzlich möglich, Fische mit langdauernder Laichzeit von solchen mit kurzer zu unterscheiden (GerbiLsky 1947, zitiert n. NaUmow 1956).

Bei Fischen mit kurzer Dauer der Laichzeit reift einmal im Jahr eine bestimmte Menge an Eiern aus der Masse der Reserve-Oozyten heran. Man wird bei diesem Typ auf dem histologischen Schnitt außer den jüngsten Stadien (Oogonien, kleine Oozyten) nur eine bestimmte Größengruppe von Oozyten antreffen, deren mittlere Größe bis zum Eintritt der Laichzeit ständig wächst. Die reifen Eier werden binnen kurzer Zeit abgelegt.

Bei Fischen mit längerwährender Laichzeit gehen die Größen der Oozyten kontinuierlich ineinander über. Die jeweils reifen Eier werden abgelegt, so daß der Laichvorgang in Portionen erfolgt und sich über einen längeren Zeitabschnitt erstreckt.

Naumow (1956) macht darauf aufmerksam, daß Fische mit ausgeprägt portionsweisem Laichen bisher nicht bekannt sind, allenfalls gibt es Ơbergänge. Seiner Meinung nach sollte die Grenze zwischen beiden Gruppen gezogen werden bei anderthalb- bis zweiwöchiger Laichzeit.

Auf einen interessanten Gesichtspunkt macht Quastm (1956) aufmerksam. Er stellt fest, daß Blennius pholis L. im Frühjahr und Sommer laicht über einen Zeitraum von fünf Monaten, während Centronotus gunnellus (L.) zwei Monate lang Ende des Winters bis Anfang Frühjahr seine Eier ablegt. Aus den von ihm gegebenen Diagrammen zur Zusammensetzung des Oozytenbestandes läßt sich entnehmen, daß bei Centronotus gunnellus nur eine Größengruppe sich aus dem Reservebestand gelöst hat, während sich bei Blennius pholis Übergänge finden. Nach dem eingangs erläuterten Schema müßte man also Centronotus gunnellus zu den Fischen mit kurzer, Blennius pholis zu 
denen mit langer Laichzeit rechnen. Das stimmt nicht überein mit den von Naumow gesetzten Grenzen.

Meiner Ansicht nach haben die genannten' Autoren einen wichtigen Punkt nicht klar genug herausgestellt: daß man nämlich zu unterscheiden hat zwischen der Laichzeit der Art und der des Individuums. Die Einteilung lange Laichzeit - kurze Laichzeit gilt strenggenommen nur für das Einzeltier. Dabei ist der Zeitpunkt gleichgültig, es kommt nur darauf an, daß die kurzfristigen Laicher ihre Eier auf einmal ablegen. Betrachtet man aber die Art insgesamt, so erhält das Verhältnis der Laichzeiten der Individuen ausschlaggebende Bedeutung. Das möchte ich an dem von Quassm gegebenen Beispiel erläutern. Dem Einzeltier von Centronotus gunnellus muß man auf Grund des histologischen Befundes eine kurze Laichzeit zuschreiben. Da aber einige Fische am Ende des Winters ihre Eier legen, andere erst Anfang Frühjahr, erstreckt sich die Laichzeit über zwei Monate, man müßte also von einer langdauernden sprechen. Ausschlaggebend ist, glaube ich, das histologische Bild. Für die fischereibiologische Praxis kommt es dagegen nur auf die Laichzeit der Art an.

Quasim findet eine interessante Deutung für das Verhalten der von ihm untersuchten Arten. Er vertritt den Standpunkt, daß es zusammenhängt mit der Verbreitung. Centronotus gunnellus ist eine nördliche Form (Westgrönland, Island, Norwegen, Kanal) und Blennius pholis eine südliche (Bergen bis Mittelmeer). Bei den nördlichen Formen soll das Laichgebiet zwischen Arktis und Kanal liegen, bei den südlichen zwischen Mittelmeer und Nordsee. Danach teilt er alle Fische ein. Die südlichen Formen legen ihre Eier Ende Frühjahr bis Sommer, fünf bis sechs Monate lang, die nördlichen Formen Ende Winter bis Frühjahr, nur drei bis vier Monate. Das reifende Ovar einer südlichen Art enthält Oozyten der verschiedensten Größen, das einer nördlichen Art Oozyten von ungefähr gleicher Größe, die daher auch zusammen abgelegt werden.

Die Einteilung der Fische in nördliche und südliche Arten ist zweifellos sehr schroff und unbiologisch. Diese Vereinfachung gibt aber zunächst eine Grundlage für weitere Untersuchungen. Keineswegs soll durch sie die bewährte tiergeographische Einteilung (ЕкмаN 1935) ersetzt werden. Ein Einfluß der Umgebung auf die Reifungsvorgänge und den Ablauf des Laichens ist unbedingt anzunehmen und für eine Reihe von Fischen nachgewiesen. So soll die Periodizität der Wanderungen des Herings durch die Periodizität der hydrologischen Faktoren bedingt sein (GLebow 1938). Der Zeitpunkt des Ablaichens ist nach Ambros (1931) von der Temperatur abhängig. Der atlantische Hering reagiert auf eine Temperaturänderung von $0,2^{\circ} \mathrm{C}$ (Shelford und Powers 1915). Ebenso spielen Salzgehalt und Licht eine große Rolle (Naumow 1956, Schtrajch und Swetosarow 1940, Smirnow 1946 und andere). Daraus muß man folgern, daß verschiedene Populationen einer Art auch verschiedenen Reifungstypen angehören können. Der Reifungstyp ist also nicht genetisch festgelegt, sondern nur stoff wechselphysiologisch bedingt und unterliegt daher in besonderem Maße dem Einfluß äußerer Faktoren. Dafür bietet von den untersuchten Arten die Sardelle ein Beispiel. Sie laicht im Mittelmeer und Atlantik etwa am Standort und über lange Zeit von April bis September, in der Nordsee ist sie dagegen ausgesprochener Wanderfisch und laicht im Juni und Juli (Aurich, brieflich). In strengem Sinne dürfte man also nicht von „nördlicher Art“ oder „südlicher Art" sprechen, sondern nur von einer „nördlich oder südlich verbreiteten und entsprechend beeinflußten Population" der 
Art, sofern das Gesamtverbreitungsgebiet nicht auf ein Areal geringer geographischer Breitendifferenz beschränkt ist. In diesem Sinne werden im folgenden die Ausdrücke "nördliche und südliche Art" gebraucht.

Die Erklärung für die Verschiedenheiten findet sich nach Quasım in der Regel von Orton (1920): Arten, die den wärmeren Grenzen ihres Verbreitungsgebietes näher sind, laichen während der kälteren Monate des Jahres, dagegen Arten, die den kälteren Grenzen ihrer Verbreitung näher sind, in den wärmeren Monaten.

Da (weiter n. Quasim) die Larven in der planktonreichen Zeit dasein müssen und die Embryonalentwicklung in der kalten Jahreszeit länger dauert, muß der Fisch um so eher laichen. Weil Temperatur und Futter in der Laichzeit ihr jährliches Minimum erreicht haben, sind die Lebensbedingungen für den fortpflanzungsbereiten Fisch zu schlecht, als daß er die Reifung der folgenden Oozytenschübe in Gang halten könnte. Daher laicht er auf einmal ab. Das stimmt gut mit den bekannten Tatsachen überein. $\mathrm{Zu}$ bedenken ist in diesem Falle noch, daß viele Fische (wie zum Beispiel der Hering) während der Laichzeit kein Futter aufnehmen. Andere Arten, wie der Wittling, fressen auch in der Legeperiode, die sich dann über einen längeren Zeitraum erstreckt (MesstorfF 1959).

Ein interessanter Zusammenhang ergibt sich bei den Fischen mit Brutpflege. Bei südlichen Arten bewacht stets das Männchen die Eier, während das Weibchen frißt, um den notwendigen Stoffvorrat zu sammeln (Blennius-, Clinus- und Gobius-Arten). Bei nördlichen Arten ist es gleichgültig, welcher der beiden Partner die Wache übernimmt, da die Futterlage so schlecht ist, daß die Weibchen nicht mehr laichen. Bei einer Blennius-Art wacht das Weibchen (Schultz 1932, zitiert n. Quasim 1956), während es bei Centronotus gunnellus beide sind (Quasim 1956).

\section{Die Bestimmung der Fruchtbarkeit}

I. Oozytenwachstum und Fruchtbarkeitsbestimmung bei einigen TeleosteerArten

Für die Erhaltung der Art ist das Verhältnis von Zuwachs und Verlust von ausschlaggebender Bedeutung. Das bedeutet für die marinen Teleosteer: je größer die Gefahr, durch biotische und abiotische Einflüsse vernichtet zu werden, desto mehr Eier. Dabei ist grundsätzlich anzunehmen, daß ökologisch gleichbelastete Arten eine ähnliche Eizahl hervorbringen.

Die Ermittlung der Fruchtbarkeit stieß nicht nur auf praktische, sondern vor allem auf theoretische Schwierigkeiten. Da man das Zahlenmaterial zu gewinnen suchte, indem man die Ovarien verarbeitete, ergab sich die Frage: welche Oozytengruppen müssen mitgezählt werden? Nur die Gruppe der größten Eier oder auch noch kleinere Oozyten? Fulton (1897) zählte sämtliche in einem Ovar befindliche Stadien. Die Erscheinung, daß die Größengruppen untereinander verschieden sind, glaubt er dadurch erklären zu können, daß sich der Zeitraum des Laichens über eine längere Zeit erstreckt. Auch CunNingham (1893-95) ist der Ansicht, daß die Mehrzahl der Eier der Scholle jedes Jahr völlig neu heranwächst, weil die Zahl der Oozyten nach der Laichzeit um vieles geringer sei als die Zahl der abgelegten Eier. Für die Kliesche ist 
WhEeler (1924) der gleichen Meinung. Sämtliche vorhandenen Eier sollen abgelaicht werden. BoHL (1957) hat demgegenüber nachgewiesen, daß die Reifungsphase der Kliescheneier länger als ein Jahr dauert. Franz betont schon 1910, daß die Scholleneier etwa drei Jahre zu ihrer Entwicklung brauchen.

Es müssen also im Ovar immer Stadien vorhanden sein, die nicht der nächsten, sondern erst einer der folgenden Laichzeiten angehören. Nach den in Abschnitt VI getroffenen Feststellungen stößt die Bestimmung der Fruchtbarkeit bei Fischen mit kurzer Laichzeit auf keine wesentlichen Schwierigkeiten. Es kommt nur darauf an, vermittels einer Methodik, die gute Ergebnisse liefert, jeweils die Oozytengruppe auszuzählen, die sich von den Reserve-Eiern gelöst hat. Schon zu einem frühen Zeitpunkt ist das möglich. Schwieriger ist die Zählung bei Fischen mit langer Laichperiode. Erst auf einem relativ späten Entwicklungsstadium sondern sich die Oozytengruppen klar genug voneinander. Aus dem Vergleich laichreifer und ausgelaichter Ovarien läßt sich entnehmen, welche Oozytengruppen abgelegt werden.

Für die Beurteilung der Fruchtbarkeit habe ich außer eigenen auch die Zahlen anderer Autoren herangezogen, soweit dies sinnvoll schien.

In den graphischen Darstellungen ist auf der Abszisse der größte Durchmesser der Oozyten aufgetragen. Die Einteilung der Größengruppen erfolgte nach den Angaben in Strich Okularmikrometerteilung. Um eine Vorstellung der wirklichen Abmessungen zu geben, wurde ein zweiter Maßstab in Millimetern aufgetragen. Auf der Ordinate kann die Häufigkeit $\mathrm{H}($ in $\%$ ) abgelesen werden. In der Legende zu den Abbildungen finden sich die Longitudo totalis des Fisches (in $\mathrm{cm}$ ), das Datum des Fanges und in Klammern die Protokollnummer. Die in den Tabellen angegebenen Fangortabkürzungen bedeuten: $\mathrm{L}=$ List/SyIt, $\mathrm{H}=$ Helgoland, $\mathrm{D}=$ übrige Deutsche Bucht.

\section{Agonus cataphractus L.}

Die mittlere Eizahl des Steinpickers liegt bei 1300 Eiern pro Laichsaison. Der Eidurchmesser beträgt etwa $2 \mathrm{~mm}$. Die Eier werden von Januar bis April abgelegt. Sie werden durch eine schleimige Masse zusammengehalten, die

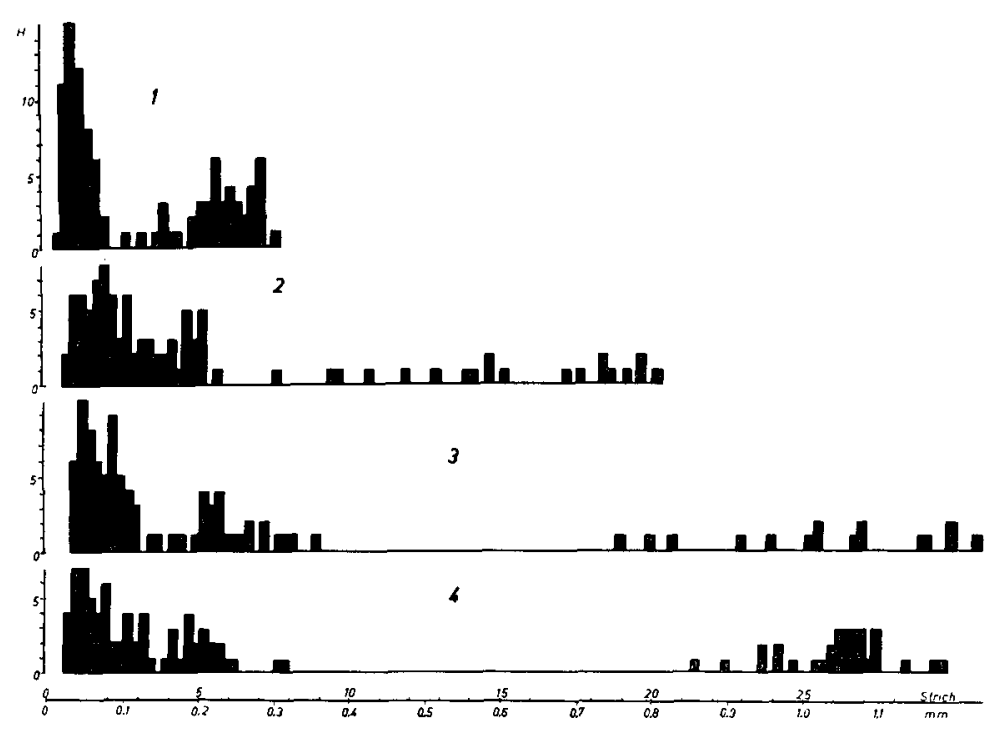

Abb. 26: Größengruppen der Oozyten im Ovar von Agonus cataphractus 1. $16 \mathrm{~cm}, 8.9 .58$ (A 5) $-2.16 \mathrm{~cm}, 26.11 .58$ (A 7) $-3.16 \mathrm{~cm}, 26.11 .58$ (A 8) 4. $13 \mathrm{~cm}, 17.12 .58$ (A 9) 
kurze Zeit nach dem Eintritt in das Meerwasser erhärtet und so eine "tertiäre“ Eihülle bildet (ANkel 1933).

Die Zahlenwerte sind in Tabelle 1 zusammengestellt. In den Tieren 2-5 ist das Gelege noch im Wachsen, allenfalls sind nicht abgelegte Eier vorhanden (2 und 4). Aus der Abb. 26, 1 geht hervor, daß im September die Reifung der Oozyten eingesetzt hat. Aus der Gruppe der Reserve-Eier haben sich einige herausgelöst. Im November ist ein breit ausgezogenes Feld vorhanden (Abb. 26, 2), bei anderen Tieren hat sich die Gruppe der reifenden Eier zu diesem Zeitpunkt schon völlig getrennt von dem Reservebestand (Abb. 26, 3). Die etwas Zurückgebliebenen holen auf (Abb. 26, 4), und alle wachsen zu einheitlicher Größe heran.

Die Trennung der Größengruppen ist sehr deutlich ausgeprägt. Kurz vor Beginn der Laichzeit gibt es keine kontinuierlichen Ubergänge zwischen reifen und Reserve-Eiern. Es ist aber außer dem reifen Gelege und den jüngsten Reserve-Oozyten unter 0,08 mm Durchmesser eine weitere Gruppe vorhanden, die das Gelege der nächsten Laichzeit bildet. Die endgültige Trennung von mittlerer und reifender Gruppe erfolgt bei etwa $0,3 \mathrm{~mm}$ Durchmesser. Bis zum September bleibt die mittlere Gruppe unter dieser Größe, dann setzt ein schnelles Wachstum ein, während gleichzeitig jüngere Oozyten auf den Stand der mittleren nachwachsen. Aus diesem Rhythmus möchte ich schließen, daß die Entwicklung einer Eiportion bis zur Ablage zwei Jahre dauert. Die Zahlen

Tabelle 1

Oozytenbestand im Ovar von Agonus cataphractus

\begin{tabular}{|c|c|c|c|c|c|c|}
\hline Nr. & Datum & Länge & Ort & $\begin{array}{c}\text { bis } 0,12 \\
\text { mm }\end{array}$ & $\begin{array}{c}\text { Oozyten } \\
0,12-0,30 \\
\mathrm{~mm}\end{array}$ & $\begin{array}{c}\text { über } 0,30 \\
\mathrm{~mm}\end{array}$ \\
\hline 1 & 8. 9.58 & 15 & L & 400 & 2700 & 1412 \\
\hline 2 & 8.9 .58 & 15 & $\mathrm{~L}$ & 500 & 2800 & 18 \\
\hline 3 & 8. 9.58 & 14 & $\mathrm{~L}$ & 300 & 2600 & - \\
\hline 4 & 8. 9.58 & 15 & $\mathrm{~L}$ & 4300 & 5500 & 190 \\
\hline 5 & 8. 9.58 & 16 & L & 4800 & 3200 & - \\
\hline 6 & 26.11 .58 & 13 & $\mathrm{~L}$ & 10000 & 1700 & 1500 \\
\hline 7 & 26.11 .58 & 16 & $\mathrm{~L}$ & 19300 & 3900 & 6 \\
\hline 8 & 26.11 .58 & 16 & $\mathrm{~L}$ & 12400 & 4500 & 2375 \\
\hline 9 & 17.12 .58 & 13 & $\mathrm{H}$ & 3150 & 1200 & 1062 \\
\hline 10 & 17.12 .58 & 15 & $\mathrm{H}$ & 6400 & 1600 & 1800 \\
\hline 11 & 21. 3.60 & 15 & $\mathrm{H}$ & - & - & 1644 \\
\hline 12 & 22. 3.60 & 13 & $\mathrm{H}$ & - & 一 & 797 \\
\hline 13 & 22. 3.60 & 13 & $\mathrm{H}$ & - & 一 & 946 \\
\hline 14 & 22. 3.60 & 17 & $\mathrm{H}$ & - & - & 1706 \\
\hline 15 & 23. 3.60 & 14 & $\mathrm{H}$ & 一 & $\ldots$ & 1316 \\
\hline 16 & 23. 3.60 & 15 & $\mathrm{H}$ & - & - & 1094 \\
\hline 17 & 24. 3.60 & 14 & $\mathrm{H}$ & - & - & 1227 \\
\hline 18 & $24, \quad 3.60$ & 14 & $\mathrm{H}$ & - & - & 927 \\
\hline 19 & 25.3 .60 & 14 & $\mathrm{H}$ & - & - & 1123 \\
\hline 20 & 1. 4.60 & 15 & $\mathrm{H}$ & - & $\ldots$ & 1260 \\
\hline
\end{tabular}

Nr. 1-3 der Tabelle sind schwer zu deuten. Die geringe Anzahl der ReserveOozyten läßt sich kaum allein durch fehlerhafte Probenentnahme erklären. Es ist denkbar, daß durch Störungen in der oogonialen Teilungsfolge ein Defizit an Reserve-Oozyten auftritt. Trotzdem wird die Gruppe der mittleren Oozyten auf ihrem normalen Stand gehalten. Die Regulation der Gelegegröße kann 
Tabelle 2

Mittlere Fruchtbarkeit von Agonus cataphractus

\begin{tabular}{ccc} 
Länge & mittlere Fruchtbarkeit & Probenzahl \\
\hline 13 & 1050 & 4 \\
14 & 1150 & 4 \\
15 & 1450 & 5 \\
17 & 1700 & 1
\end{tabular}

daher nicht auf einem Gleichgewichtsprinzip Reserve-Oozyten - mittlere Oozyten - reifes Gelege beruhen, allenfalls auf einem Balancezustand zwischen den beiden letzten Größengruppen. Dafür würden auch die Zahlen der Tabelle 1 sprechen, aus denen zu erkennen ist, daß eine gute Übereinstimmung zwischen den ältesten Oozytengruppen besteht. Es sind etwas mehr mittlere Oozyten vorhanden als reife. Während der Entwicklung muß also ein Teil zurückbleiben, vielleicht degenerieren und beeinflußt die Gonade dann in dem in Abschnitt $V$ besprochenen Sinne.

Nach dem histologischen Befund nimmt der Laichvorgang nur kurze Zeit in Anspruch, was mit der Beobachtung gut übereinstimmt. Im Frühjahr 1960 laichten die Agonus-Weibchen im Helgoländer Gebiet binnen etwa 14 Tagen ab (ungefähr 25. 3.-8, 4.). Danach waren in den schlaffen Ovarien nur noch weißlichtrübe, degenerierte Eier anzutreffen.

Tabelle 3

Oozytenbestand im Ovar von Limanda limanda

\begin{tabular}{|c|c|c|c|c|c|}
\hline \multirow{2}{*}{ Nr. } & \multirow{2}{*}{ Datum } & \multirow{2}{*}{ Länge } & \multirow{2}{*}{ Ort } & \multicolumn{2}{|c|}{ Oozyten } \\
\hline & & & & bis $0,12 \mathrm{~mm}$ & über $0,12 \mathrm{~mm}$ \\
\hline 1 & 8. 9.58 & 25 & $\mathrm{D}$ & 1141150 & 285200 \\
\hline 2 & 8. 9.58 & 23 & $\mathrm{D}$ & 1164700 & 111200 \\
\hline 3 & 8. 9.58 & 93 & $\mathrm{D}$ & 256900 & - \\
\hline 4 & 8. 9.58 & 23 & $\mathrm{D}$ & 869000 & - \\
\hline 5 & 8. 9.58 & 27 & $\mathrm{D}$ & 713400 & 237800 \\
\hline 6 & 8. 9.58 & 26 & $\mathrm{D}$ & 1696000 & - \\
\hline 7 & 8. 9.58 & 24 & $\mathrm{D}$ & I 696000 & 188600 \\
\hline 8 & 8. 9.58 & 23 & D & 109200 & 163800 \\
\hline 9 & 8. 9.58 & 22 & $\mathrm{D}$ & 724500 & - \\
\hline 10 & 8. 9.58 & 21 & $\mathrm{D}$ & 731800 & 35100 \\
\hline 11 & 8. 9.58 & 22 & $\mathrm{D}$ & 532200 & 76000 \\
\hline 12 & 8. 9.58 & 28 & D & 1319600 & - \\
\hline 13 & 8. 9.58 & 27 & $\mathrm{D}$ & 1191800 & 12000 \\
\hline 14 & 8. 9.58 & 23 & $\mathrm{D}$ & 984800 & - \\
\hline 15 & 8. 9.58 & 22 & $\mathrm{D}$ & 767300 & - \\
\hline 16 & 26.11 .58 & 16 & $\mathrm{~L}$ & 306000 & 85000 \\
\hline 17 & 27.11 .58 & 21 & $\mathrm{~L}$ & 753800 & 442700 \\
\hline 18 & 27.11 .58 & 22 & $\mathrm{~L}$ & 957000 & 72000 \\
\hline 19 & 27.11 .58 & 24 & $\bar{L}$ & 169500 & 29900 \\
\hline 20 & 17.12 .58 & 15 & $\mathrm{H}$ & 737700 & 491800 \\
\hline 21 & 17.12 .58 & 20 & $\mathrm{H}$ & 655500 & 436900 \\
\hline 22 & 17.12 .58 & 21 & $\mathrm{H}$ & 855500 & 524300 \\
\hline 23 & 17. 12.58 & 21 & $\mathrm{H}$ & 881100 & 143400 \\
\hline 24 & I7. 12.58 & 22 & $\mathrm{H}$ & 515500 & 421700 \\
\hline 25 & 17. 12.58 & 22 & $\overrightarrow{\mathrm{H}}$ & 837300 & 236200 \\
\hline 26 & 17.12 .58 & 23 & $\mathrm{H}$ & 720700 & 399700 \\
\hline 27 & 17. 12.58 & 23 & $\mathrm{H}$ & 621700 & 450200 \\
\hline 28 & 17.12 .58 & 26 & $\mathrm{H}$ & 429900 & 701600 \\
\hline
\end{tabular}


Auf Grund der kurzfristigen Laichperiode und seiner Verbreitung (NOAtlantik, Nordsee, westliche Ostsee) müssen wir Agonus cataphractus als nördliche Form bezeichnen. Die Bestimmung der Fruchtbarkeit ist relativ einfach. Es können dazu etwa vom Dezember an alle Oozyten über $0,6 \mathrm{~mm}$ Durchmesser verwendet werden.

\section{Limanda limanda (L.)}

Über die Kliesche liegen aus letzter Zeit ausführliche Zählungen vor. Dennoch habe ich nicht darauf verzichtet, selbst Material zu bearbeiten, um den Wert der Methode zu prüfen. Die Ergebnisse sind in Tabelle 3 zusammengefaßt. Bei etwa 0,12 mm Durchmesser liegt die Größengrenze, an der sich Reserve-Oozyten und reifendes Gelege scheiden. Es ist von vornherein klar, daß nur die Eier ausgezählt werden dürfen, die sich in der Größe deutlich von den übrigen gelöst haben. Damit schmilzt das Material sofort auf einen kleinen Bruchteil zusammen, der allein für die Bestimmung der Fruchtbarkeit maßgebend ist. Andererseits darf das Gelege nicht so reif sein, daß die Möglichkeit besteht, daß ein Teil der Eier bereits abgelaicht ist. Ich hebe diese grundsätzlichen Anforderungen noch einmal hervor, weil die von mir erzielten Ergebnisse nicht übereinstimmen mit denen von KäNDLER und PIRwiTz (1957). Dagegen passen sie gut zu den Werten von BoHL (1957). Die
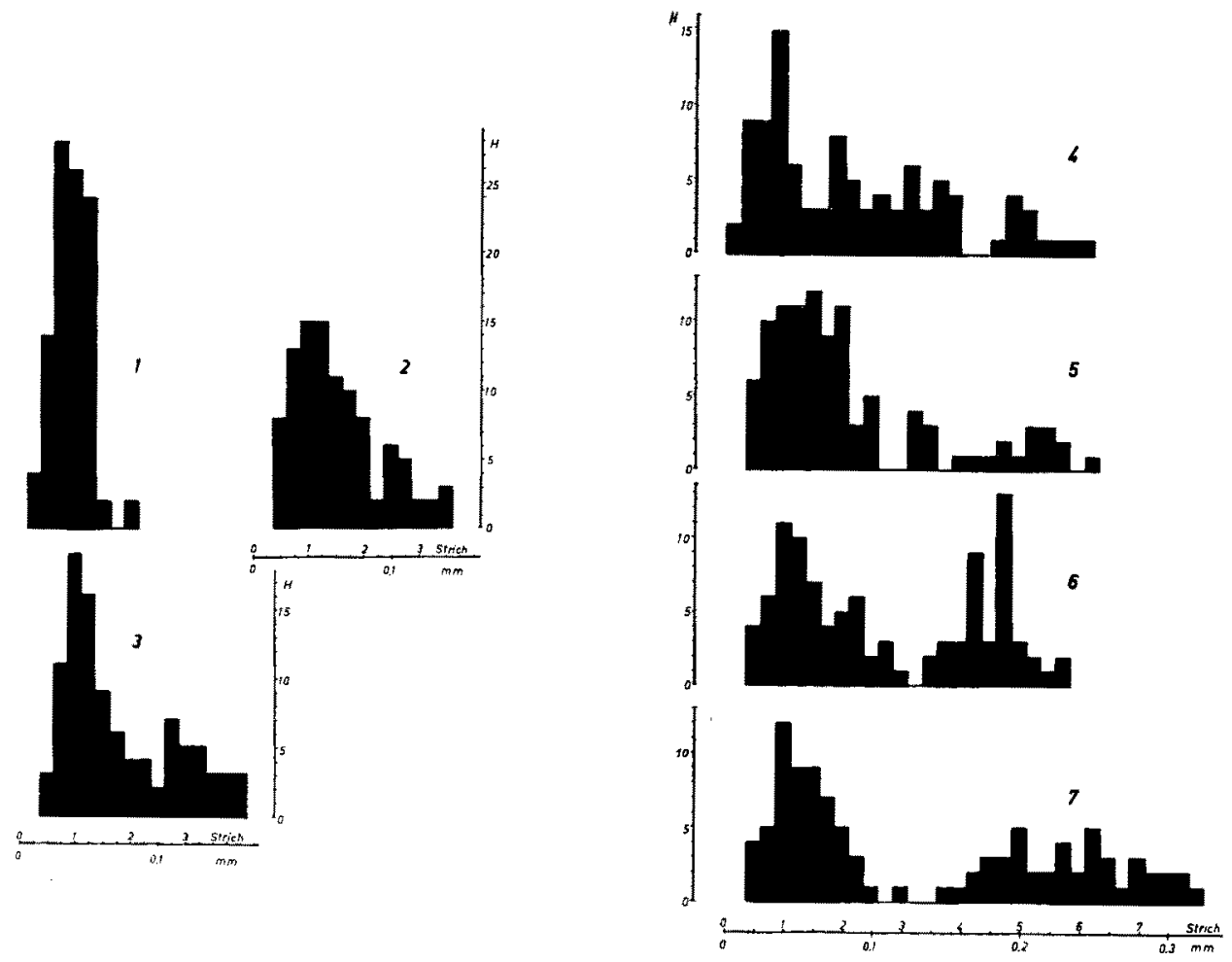

Abb. 27: Größengruppen der Oozyten im Ovar von Limanda limanda $1.22 \mathrm{~cm}, 8.9 .58(\mathrm{~K} 15)-2.22 \mathrm{~cm}, 27.11 .58(\mathrm{~K} 18)-3.16 \mathrm{~cm}, 26.11 .58(\mathrm{~K} 16)$ $4.21 \mathrm{~cm}, 27.11 .58(\mathrm{~K} 17)-5.22 \mathrm{~cm}, 17.12 .58(\mathrm{~K} \mathrm{25})-6.15 \mathrm{~cm}, 17.12 .58(\mathrm{~K} \mathrm{20})$ $7.22 \mathrm{~cm}, 17.12 .58(\mathrm{~K} \mathrm{24})$ 
Fruchtbarkeit wäre nach KäNDLER und PiRwiTz wesentlich geringer als nach ВонL und meinen Zählungen (Tabelle 4). Mein Material ist aus den oben angeführten Gründen sehr klein, da es aber mit dem von BoHL weitgehend

Tabelle 4

Mittlere Fruchtbarkeit von Limanda limanda

\begin{tabular}{|c|c|c|c|c|}
\hline Länge & $\begin{array}{l}\text { n. K.̈̈NDLER } \\
\text { u. PIRWITZ }\end{array}$ & $\begin{array}{c}\text { mittlere Ei } \\
\text { n. BoHL }\end{array}$ & $\begin{array}{l}\text { n. eigenen } \\
\text { Zählungen }\end{array}$ & Probenzah \\
\hline 14,5 & - & 79000 & - & 5 \\
\hline 16,0 & - & - & 85000 & 1 \\
\hline 17,5 & - & 136000 & - & 5 \\
\hline 20,5 & - & 230000 & - & 5 \\
\hline 22,0 & - & - & 329000 & 2 \\
\hline 23,0 & - & - & 425000 & 2 \\
\hline 23,5 & - & 390000 & - & 5 \\
\hline 25,5 & 131000 & - & - & 9 \\
\hline 26.0 & - & - & 702000 & 1 \\
\hline 26,5 & - & 643000 & - & 5 \\
\hline 27,0 & 162000 & - & - & 36 \\
\hline 28,8 & 200000 & - & - & 20 \\
\hline 30.3 & - & 938000 & - & 4 \\
\hline 30,4 & 260000 & - & - & 5 \\
\hline
\end{tabular}

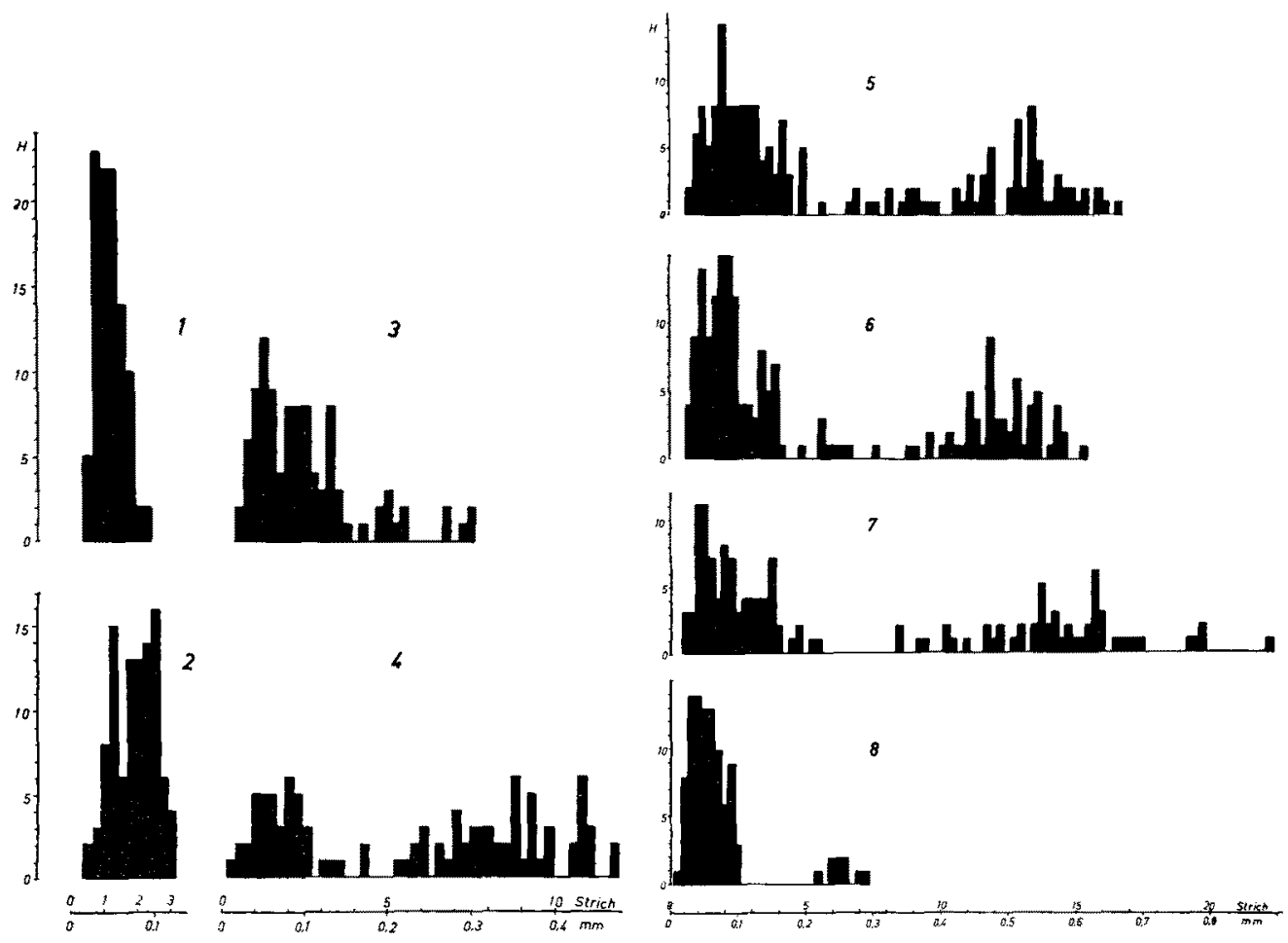

Abb. 28: Größengruppen der Oozyten im Ovar von Plauronectes platessa

$1.22 \mathrm{~cm}, 8.9 .58(\mathrm{~S} 4)-2.23 \mathrm{~cm}, 8.9 .58(\mathrm{~S} 25)-3.38 \mathrm{~cm}, 8.9 .58$ (S 6)

4. $31 \mathrm{~cm}, 8.9 .58(\mathrm{~S} 5)-5.34 \mathrm{~cm}, 8.9 .58(\mathrm{~S} 99)-6.38 \mathrm{~cm}, 8.9 .58$ (S 1)

$7.33 \mathrm{~cm}, 8.9 .58$ (S 3$)-8.22 \mathrm{~cm}, 8.9 .58(27)$ 
übereinstimmt, habe ich auf eine ausführliche Untersuchung verzichtet, die über den Rahmen dieser Arbeit hinausgegangen wäre.

Wesentlich ist, daß auch bei der Kliesche die heranreifende Oozytengruppe sich klar vom Reservebestand löst. In dem in Abb. 27, 7 ausgewerteten Ovar findet man neben Oozyten der Stadien I und IV einige zu Stadium III gehörige. Diese reifen bis zur Laichzeit noch heran.

Auf Grund dieses Befundes und der Verbreitung (Biskaya bis Murmanküste) ist die Kliesche als nördliche Form zu bewerten.

\section{Pleuronectes platessa $\mathrm{L}$.}

Bei der Scholle hat die Oozytenreifung im September bereits eingesetzt. Die Tiere, deren Meßwerte in der Abbildung 28 dargestellt sind, wurden alle zur gleichen Zeit gefangen. Dadurch wird deutlich, daß die Eientwicklung durchaus individuell verschieden ist. Bei den jüngsten Schollen (Abb. 28, 1 und 2) finden sich nur Reserve-Oozyten im Ovar. Auf dem Querschnitt erkennt man, daß neben Eiern im Stadium I erst Übergänge zu Stadium II vorhanden sind. Diese Weibchen sind noch nicht reif. Die älteren Fische enthalten in ihrem Eierstock schon ein weiterentwickeltes Gelege (Abb. 28, 7). Neben den Reserve-Eiern im Stadium I finden sich ausschließlich andere im Stadium IV. Übergänge sind nicht festzustellen. Für die Bestimmung der Fruchtbarkeit kommen nur Oozyten von mehr als 0,2 mm Durchmesser in Frage. Die Scholle ist nach dem histologischen Bild und ihrer Verbreitung (Portugal bis Weißes Meer) als nördliche Form zu bewerten.

Tabelle 5

Oozytenbestand im Ovar von Pleuronectes platessa

\begin{tabular}{|c|c|c|c|c|c|}
\hline \multirow{2}{*}{$\mathrm{Nr}$. } & \multirow{2}{*}{ Datum } & \multirow{2}{*}{ Länge } & \multirow{2}{*}{ Ort } & \multicolumn{2}{|c|}{ Oozyten } \\
\hline & & & & bis $0,2 \mathrm{~mm}$ & über $0,2 \mathrm{~mm}$ \\
\hline 1 & 8. 9.58 & 38 & $\mathrm{D}$ & 284400 & 124700 \\
\hline 2 & 8. 9.58 & 21 & $\mathrm{D}$ & 72000 & - \\
\hline 3 & 8. 9.58 & 33 & $\mathrm{D}$ & 161000 & 93600 \\
\hline 4 & 8. 9.58 & 29 & $\mathrm{D}$ & 23100 & - \\
\hline 5 & 8. 9.58 & 31 & $\mathrm{D}$ & 89500 & - \\
\hline 6 & 8. 9.58 & 38 & $\mathrm{D}$ & 330700 & 53800 \\
\hline 14 & 29.3 .60 & 22 & $\mathrm{H}$ & 141600 & $\ldots$ \\
\hline 25 & 8. 9.58 & 23 & $\mathrm{H}$ & 167900 & - \\
\hline 26 & 8. 9.58 & 23 & $\mathrm{H}$ & 175800 & 一 \\
\hline 27 & 8. 9.58 & 22 & $\mathrm{H}$ & 209100 & 27500 \\
\hline 99 & 8. 9.58 & 34 & D & 223100 & 127500 \\
\hline
\end{tabular}

4. Pleuronectes flesus L.

Wie bei den beiden anderen untersuchten Plattfischen löst sich auch bei der Flunder eine Oozytengruppe völlig vom Reservebestand los. Es sind keine Übergänge festzustellen (Abb. 29, 2-4). Für die Bestimmung der Fruchtbarkeit kommen Oozyten über 0,2 mm Durchmesser in Frage. Legt man dieses Maß zugrunde, dann ergeben sich die Werte der Tab. 6. Ahnlich wie bei der Kliesche differieren diese Werte, wenn auch nicht so stark, gegenüber denen von KäNdler und Pirwitz (1957). Insbesondere scheint mir der von den beiden Autoren für die Größengruppe 26,0-27,9 cm angegebene Wert zu niedrig zu liegen. Der Sprung von dieser zur nächsten Gruppe ist beträchtlich.

Auf dem Querschnitt durch ein Ovar der in Abb. 29, 4 dargestellten Phase 
findet man nur Oozyten der Stadien I und IV. Es gibt hier wie bei den Größengruppen keinerlei UUbergänge.

Man muß demnach feststellen, daß die untersuchten Flundern der nördlichen Population angehören. Das Verbreitungsgebiet erstreckt sich vom WeiBen Meer über das Mittelmeer bis zum Schwarzen Meer.
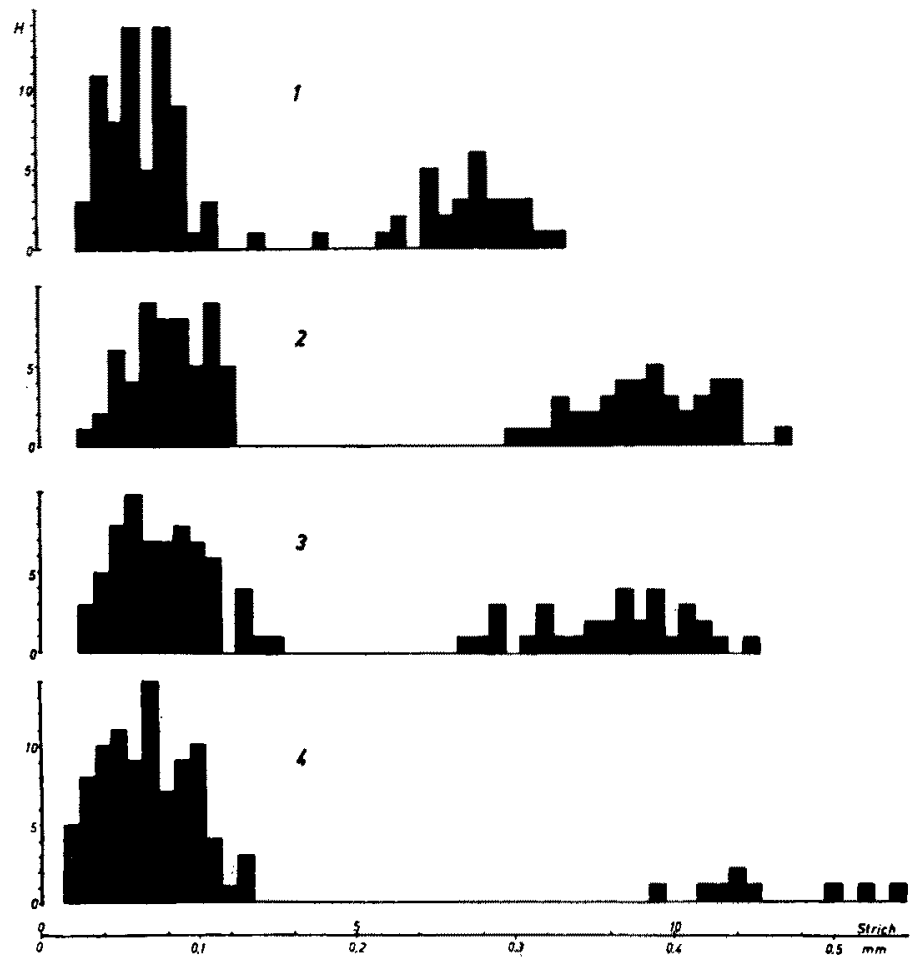

Abb. 29: Größengruppen der Oozyten im Ovar von Pleuronectes flesus 1. $25 \mathrm{~cm}, 26.11 .58$ (F 2) - 2.27 cm, 26.11.58 (F 5) - 3. $30 \mathrm{~cm}, 8.9 .58$ (F 1) $4.23 \mathrm{~cm}, 26.11 .58$ (F 3)

Tabelle 6

Oozytenbestand im Ovar von Pleuronectes flesus

\begin{tabular}{lrrrrr} 
Nr. & Datum & Länge & Ort & bis 0,2 mm & Oozyten \\
& & & & & \\
\hline I & 8.9 .58 & 30 & D & 821000 & 777600 \\
2 & 8.9 .58 & 25 & D & 407200 & 392600 \\
3 & 26.11 .58 & 23 & L & 662200 & 211300 \\
4 & 26.11 .58 & 24 & L & 1661500 & 423900 \\
5 & 26.11 .58 & 27 & L & 1012600 & 626300
\end{tabular}

\section{Solea solea (L.)}

Über die Seezunge liegen mir nur zwei Stichproben vor. Beide stammen vom September. Während die eine (Abb. 30) abgelaicht hat, finden sich in der anderen alle Stadien vom jüngsten bis zum ältesten. Damit ist das Charakteristikum für die Einordnung von Solea solea zu den südlichen Formen gegeben. Das Verbreitungsgebiet entspricht dem histologischen Befund: es erstreckt sich vom Mittelmeer bis zur Nordsee. 


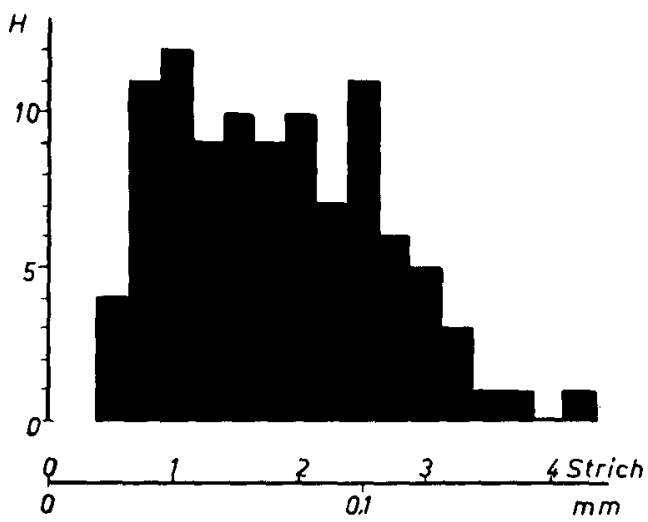

Abb. 30: Größengruppen der Oozyten im Ovar von Solea solea. $36 \mathrm{~cm}, 8.9 .58$ (SZ 2)

\section{Odontogadus merlangus (L.)}

Über den Wittling erschien erst vor kurzem eine ausführliche Arbeit (Messtorff 1959) mit einer Besprechung der Fruchtbarkeitsverhältnisse. Aus den Darstellungen der Abb. 31, 1-6 geht hervor, daß sich die Oozyten noch mitten in der Entwicklung befinden. Entsprechend sind die Werte 1-16 der Tabelle 7 (letzte Spalte) nicht als Fruchtbarkeitszahlen aufzufassen. Vielmehr spiegeln sie nur das Verhältnis der Größengruppen auf einem bestimmten Entwicklungsstadium wider. Bei den Wittlingen Nr. 22 und 23 hat sich das

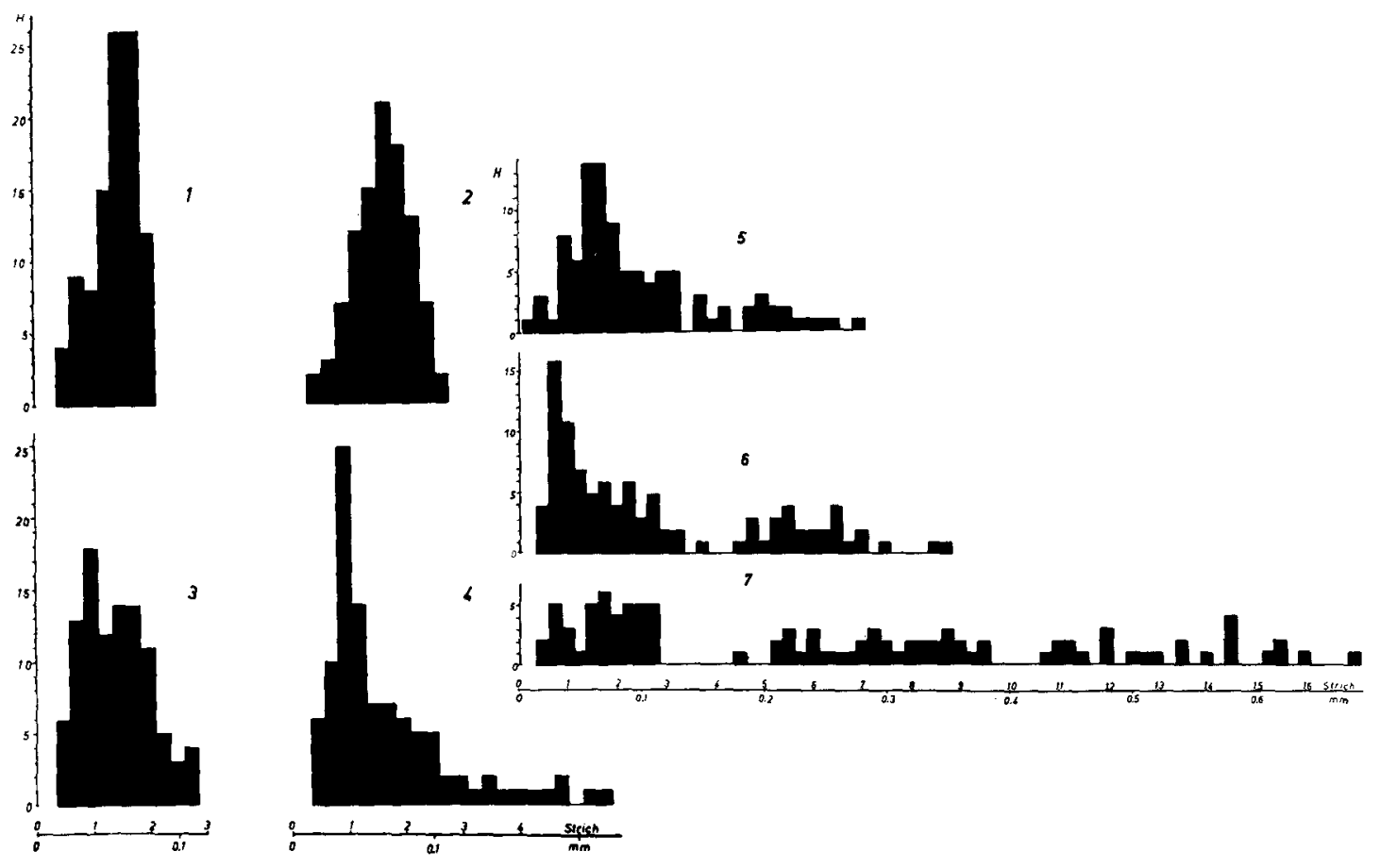

Abb. 31: Größengruppen der Oozyten im Ovar von Odontogadus merlangus

$1.25 \mathrm{~cm}, 8.9 .58$ (W 2) $-2.35 \mathrm{~cm}, 8.9 .58$ (W 1) $-3.23 \mathrm{~cm}, 17.12 .58$ (W 12)

4. ? $10.1 .59(\mathrm{~W} 15)-5.26 \mathrm{~cm}, 17.12 .58(\mathrm{~W} \mathrm{13})-6.32 \mathrm{~cm}, 19.3 .60(\mathrm{~W} 22)$

$$
7.32 \mathrm{~cm}, 20.3 .60(\mathrm{~W} \mathrm{23})
$$


Gelege dagegen gelöst von den Reserve-Oozyten. Die Werte stimmen gut mit den von Messtorff gegebenen überein. Aus dem Diagramm ist zu entnehmen, daß die Größengruppen zwar gut getrennt sind, aber nicht so klar wie bei einem typisch nördlichen Fisch. Als solchen kann man den Wittling auch nicht ansprechen, da sich sein Verbreitungsgebiet vom Schwarzen Meer über das Mittelmeer bis zur Murmanküste und nach Island erstreckt. Odontogadus merlangus nimmt also eine Mittelstellung zwischen nördlichen und südlichen Formen ein, was sowohl in seiner Verbreitung wie auch im histologischen Bild zum Ausdruck kommt. Für die Bestimmung der Fruchtbarkeit sind etwa ab Februar alle Oozyten über $0,15 \mathrm{~mm}$ Durchmesser zu verwenden.

Tabelle 7

Oozytenbestand im Ovar von Odontogadus merlangus

\begin{tabular}{|c|c|c|c|c|c|}
\hline \multirow{2}{*}{ Nr. } & \multirow{2}{*}{ Datum } & \multirow{2}{*}{ Länge } & \multirow{2}{*}{ Ort } & \multicolumn{2}{|l|}{ Oozyten } \\
\hline & & & & bis $0,15 \mathrm{~mm}$ & über $0,15 \mathrm{~mm}$ \\
\hline 1 & 8. 9.58 & 35 & $L$ & 981300 & - \\
\hline 2 & 8. 9.58 & 25 & L. & 357600 & - \\
\hline 3 & 8. 9.58 & 25 & $\mathrm{~L}$ & 507400 & - \\
\hline 5 & 8. 9.58 & 30 & $\overline{\mathrm{L}}$ & 741600 & 247200 \\
\hline 6 & 8. 9.58 & 30 & $\mathrm{~L}$ & 750200 & - \\
\hline 7 & 8. 9.58 & 29 & $\mathrm{~L}$ & 684300 & - \\
\hline 8 & 8.9 .58 & 29 & $\mathrm{~L}$ & 896600 & 一 \\
\hline 9 & 8. 9.58 & 28 & $\mathbf{L}$ & $394700 \pm 20 \%$ & - \\
\hline 10 & 8. 9.58 & 25 & $\mathbf{L}$ & 448500 & - \\
\hline 11 & 17.12 .58 & 24 & $\mathrm{H}$ & 337400 & - \\
\hline 12 & 17.12 .58 & 23 & $\mathrm{H}$ & 274800 & - \\
\hline 13 & 17.12 .58 & 26 & $\mathrm{H}$ & 643800 & 321900 \\
\hline 14 & 17.12 .58 & 27 & $\mathrm{H}$ & 714900 & 321200 \\
\hline 15 & 10. 1.59 & $?$ & $\mathrm{D}$ & 714800 & 106800 \\
\hline 16 & 10. 1.59 & 26 & $\mathrm{D}$ & 348400 & 309000 \\
\hline 22 & 19.3 .60 & 32 & $\mathrm{H}$ & 1760000 & 588000 \\
\hline 93 & 20.3 .60 & 32 & $H$ & 752000 & 612000 \\
\hline
\end{tabular}

7. Engraulis encrasicholus (L.)

Die Sardelle ist eine von der westafrikanischen Küste bis in die Höhe von Bergen verbreitete Art, die ihr Laichgebiet in Nord- und Ostsee ständig ausdehnt (AURICH 1958). Thre Laichzeit erstreckt sich über einen längeren Zeitraum. Dementsprechend finden sich in den Ovarien vor und während der Laichzeit Oozyten der verschiedensten Größen und Entwicklungsphasen.

Nach Ablauf der Laichzeit im September untersuchte Ovarien zeigen eine Größengruppe von jüngsten Oozyten (Abb. 32, 1). Thr mittlerer Durchmesser beträgt etwa $0,08 \mathrm{~mm}$. Aus dieser Gruppe lösen sich allmählich einige heranreifende Eier heraus (Abb. 32, 2). Es entwickelt sich ein ganzes Feld von Oozyten mit kontinuierlichen Ubergängen (Abb. 32, 3). Davon trennt sich ein Schub (13-17000 Oozyten, Tab. 8), dessen Eier das Gelege einer Laichperiode bilden. Die Trennung ist nicht klar, sondern es sind alle Ubergänge zu den Reserve-Oozyten vorhanden (Abb. 32).

Unter mediterranen Bedingungen dürfte ein Großteil der Eier mittlerer Größe noch heranreifen. Im Nordsee-Gebiet ist damit nicht zu rechnen, so daß für die Bewertung der Fruchtbarkeit nur Oozyten über etwa $0.45 \mathrm{~mm}$ Durchmesser in Frage kommen. Damit reduziert sich die Fruchtbarkeitsziffer der 
Sardelle erheblich (Tab. 8). Interessant ist in diesem Zusammenhang, daß NAUMow (1956) für den Murmansker Hering (Clupea harengus harengus L.) zu ähnlichen Zahlen kommt.
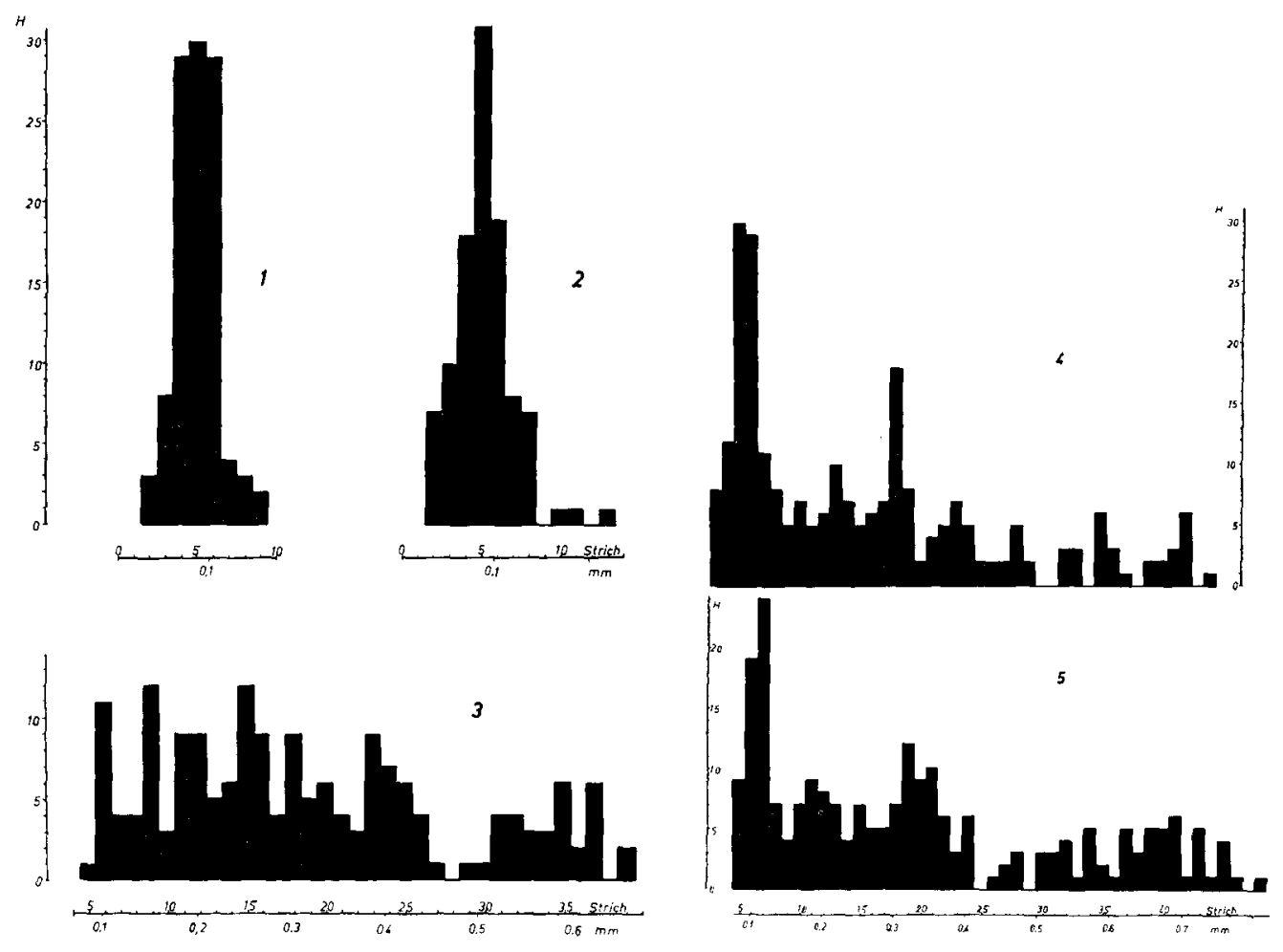

Abb. 32: Größengruppen der Oozyten im Ovar von Engraulis encrasicholus $1.16 \mathrm{~cm}, 7.9 .56$ (E 7) - 2.15 cm, 7.9.56 (E 5) - 3.17 cm, 4.7 .57 (E 3) 4. $16 \mathrm{~cm}, 4.7 .57$ (E 4$)-5.17 \mathrm{~cm}, 4.7 .57$ (E 5)

Tabelle 8

Oozytenbestand im Ovar von Engraulis encrasicholus

\begin{tabular}{ccccc} 
Nr. & Datum & Länge & Ort & Oozyten über 0,45 mm \\
\hline 1 & 7.9 .56 & 16,0 & L & - \\
2 & 7.9 .56 & 14,9 & L & - \\
3 & 4.7 .57 & 17,0 & D & 14200 \\
4 & 4.7 .57 & 15,7 & D & 13400 \\
5 & 4.7 .57 & 16,9 & D & 17200 \\
6 & 4.7 .57 & 17,9 & D & 15700
\end{tabular}

\section{Sprattus sprattus (L.)}

Bei der Sprotte liegen die Fruchtbarkeitsziffern ungefähr so hoch wie bei Sardelle und Hering. Für die Auszählung kommen Oozyten über etwa 0,2 mm Durchmesser in Betracht. Im Januar sind die Wachstumsvorgänge noch im Fluß (Abb. 33, 2 und Tab. 9, 1-3). Im März sind die Größengruppen besser. getrennt, wenn auch noch Übergänge vorhanden sind. 
Nach dem histologischen Bild muß man die Sprotte zu den südlichen Formen rechnen, da im Ovar alle Stadien der Oozytenentwicklung gleichzeitig aufzufinden sind. Die Verbreitung (Schwarzes Meer - Mittelmeer - Lofoten) spricht ebenfalls dafür, Sprattus sprattus als Fisch des südlichen Typus zu klassifizieren.

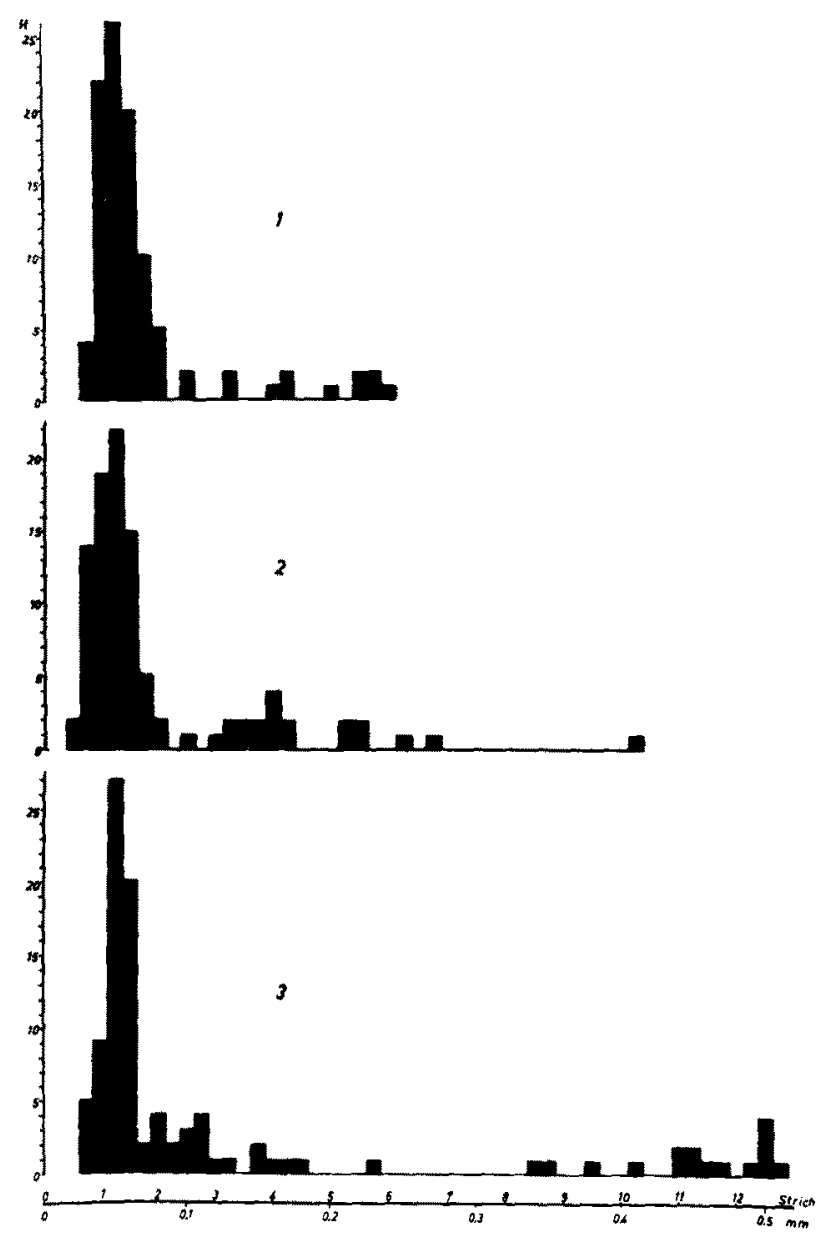

Abb. 33: Größengruppen der Oozyten im Ovar von Sprattus sprattus 1. $14 \mathrm{~cm}, 9.1 .59(\mathrm{Sp} 1)-2.16 \mathrm{~cm}, 9.1 .59(\mathrm{Sp} \mathrm{3})-3.14 \mathrm{~cm}, 9.1 .59(\mathrm{Sp} \mathrm{2})$

Tabelle 9

Oozytenbestand im Ovar von Sprattus sprattus

\begin{tabular}{lrrrrr} 
Nr. & Datum & Länge & Ort & \multicolumn{2}{c}{ Oozyten } \\
& & & & bis $0,24 \mathrm{~mm}$ & über 0,24 mm \\
\hline 1 & 9.1 .59 & 14,0 & D & 262300 & - \\
2 & 9.1 .59 & 14,0 & D & 240400 & 10800 \\
3 & 9.1 .59 & 16,0 & D & 246400 & - \\
4 & 18.3 .60 & 12,5 & D & 79600 & 12400 \\
5 & 18.3 .60 & 13,5 & D & 114500 & 14300
\end{tabular}




\section{Cottus scorpius L.}

Der Seeskorpion ist ein Musterbeispiel für einen Fisch vom nördlichen Typus. Sein Verbreitungsgebiet erstreckt sich vom Golf von Biskaya bis zum Nordpolarmeer. In seinen Ovarien trennt sich das reifende Gelege ganz klar vom Reservebestand (Abb. 34, 3 und 4). Der Grenzdurchmesser liegt bei $0,3 \mathrm{~mm}$. Auch histologisch gibt es keinerlei UUbergänge zwischen ḋen beiden Größengruppen.

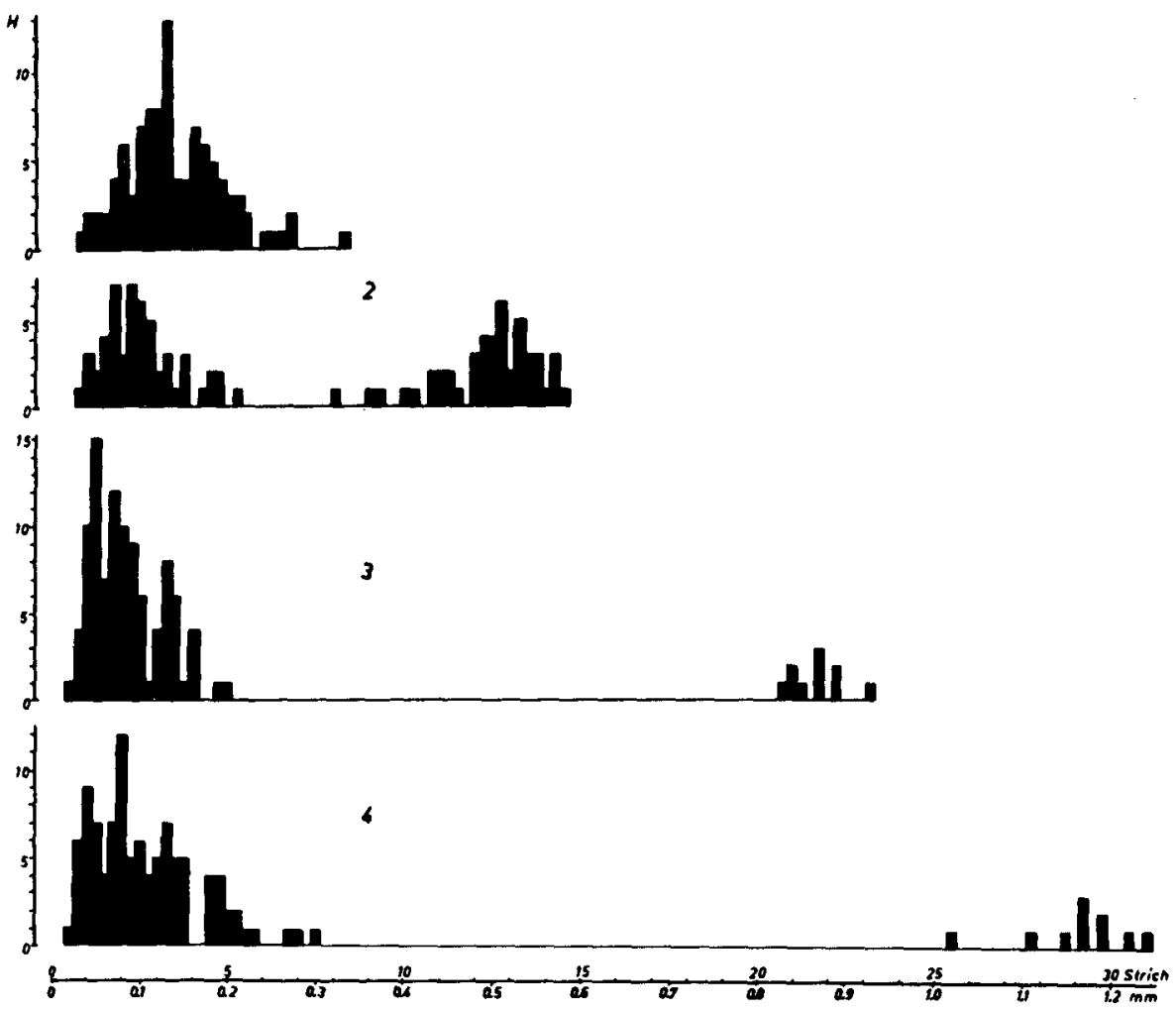

Abb. 34: Größengruppen der Oozyten im Ovar von Cottus scorpius

1. $19 \mathrm{~cm}, 9$. 4. 60 (C 9) $-2.18 \mathrm{~cm}, 8.9 .58$ (C 1) $-3.18 \mathrm{~cm}, 26.11 .58$ (C 4) 4. $19 \mathrm{~cm}, 26.11 .58$ (C 3 )

Tabelle 10

Oozytenbestand im Ovar von Cottus scorpius

\begin{tabular}{lrcccc} 
Nr. & \multirow{2}{*}{ Datum } & Länge & Ort & \multicolumn{2}{c}{ Oozyten } \\
& & & & bis $0,24 \mathrm{~mm}$ & über $0,24 \mathrm{~mm}$ \\
\hline 1 & 8.9 .58 & 18 & D & 31600 & 17300 \\
3 & 26.11 .58 & 19 & L & 74900 & 9800 \\
4 & 26.11 .58 & 18 & L & 54000 & 10500 \\
9 & 9.4 .60 & 19 & H & 79800 & 12600
\end{tabular}

10. Liparis montagui Donovan

Der Kleine Scheibenbauch ist im Helgoländer Gebiet häufiger als sein Verwandter Liparis vulgaris Fleming. Er laicht im Winter (Februar bis 


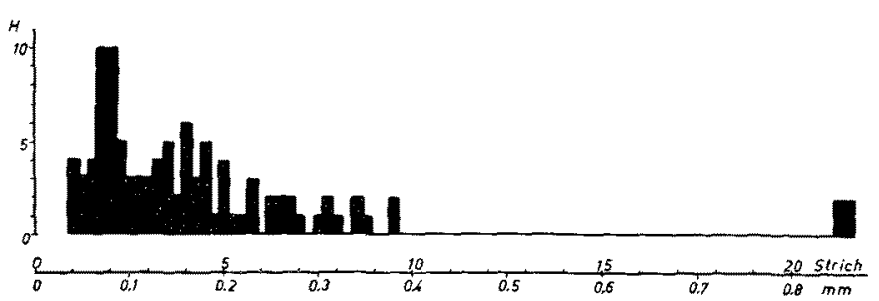

Abb. 35: Größengruppen der Oozyten im Ovar von Liparis montagui. $11 \mathrm{~cm}, 26.11 .58$ (L 1)

April). Sein Verbreitungsgebiet zieht sich vom Kanal bis zum Eismeer hin. Die Fruchtbarkeit ist vergleichbar mit der von Agonus cataphractus. Das reifende Gelege trennt sich deutlich und ohne Übergänge von dem Bestand an Reserve-Oozyten (Abb. 35), ebenso sind histologisch keine Zwischenstufen festzustellen. Der Grenzdurchmesser liegt bei $0,4 \mathrm{~mm}$. Leider stand mir nur ein Exemplar zur Verfügung.

Tabelle 11

Oozytenbestand im Ovar von Liparis montagni

\begin{tabular}{cccccc} 
Nr. & Datum & Länge & Ort & bis $0,4 \mathrm{~mm}$ & Oozyten \\
\hline 1 & 26.11 .58 & 11 & L & 54300 & 1200
\end{tabular}

II. Vergleichende Betrachtung der untersuchten Arten

Das Vorhandensein zweier Fischtypen unterschiedlicher Laichdauer kann nach den vorangegangenen Untersuchungen bestätigt werden. Bei allen ist die Laichdauer abhängig von der Verbreitung. Fische nördlicher Verbreitung

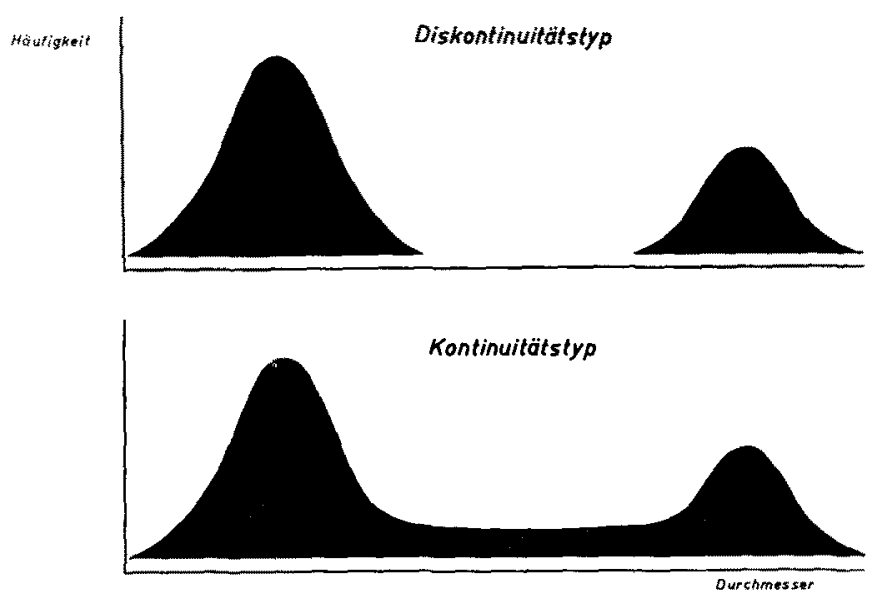

Abb. 36: Schematische Darstellung von Diskontinuitäts- und Kontinuitätstyp

laichen innerhalb kurzer Zeit. In ihren Ovarien finden sich reifende und Reserve-Oozyten ohne Ubergänge. Ich möchte diese Arten daher als Laicher des Diskontinuitätstyps bezeichnen (Abb. 36). Dazu gehören Agonus 
cataphractus, Limanda limanda, Pleuronectes platessa, P. flesus, Cottus scorpius und Liparis montagui.

Ihnen stehen Arten gegenüber mit südlichem Verbreitungsgebiet. In deren Ovarien sind Oozyten aller Größen zu finden. Die Laichzeit erstreckt sich über einen längeren Zeitraum. Histologisch sind kontinuierliche Übergänge zwischen den Wachstumsstadien festzustellen. Daher möchte ich diese Arten als solche vom Kontinuitätstypus bezeichnen (Abb. 36). Hierher gehören Solea solea, Engraulis encrasicholus und Sprattus sprattus.

Auf Grund der Größenverhältnisse der Oozyten im Ovar sind bereits früher (Jong 1940, Bertin 1958) die Begriffe "type unimodal" (entspricht dem Diskontinuitätstyp) und „type plurimodal“ (entspricht dem Kontinuitätstyp) aufgestellt worden.

Eine Mittelstellung nimmt Odontogadus merlangus ein. Es sind auch andere Fische bekannt, die zwischen den beiden Reifungstypen vermitteln und die mehrere Male im Jahr laichen (Kisselewitsch 1923, Hickling und Rutenderg 1936, Takeshita und Aikawa 1960). In unserem Gebiet wird der Wittling wahrscheinlich unter dem Einfluß der ungünstigeren äußeren Faktoren nur einmal zum Ablaichen kommen und sich dadurch von den erwähnten Arten unterscheiden.

Vergleicht man die Laichzeiten der besprochenen Arten, so ist festzustellen, daß die Fische vom Diskontinuitätstyp in der Hauptsache sehr früh im Jahre ihre Eier ablegen. Der Extremfall ist Cottus scorpius. Die Teleosteer vom Kontinuitätstyp laichen vor allem im Sommer. Der Wittling nimmt eine Mittelstellung ein. Die Laichzeiten der untersuchten Fischarten fügen sich also der Regel von Orton (1920).

\section{Das Verhältnis von unreifen und reifen Oozyten}

Aus dem bisher Dargestellten geht hervor, daß zu jeder Laichzeit eine bestimmte Menge von Oozyten heranreift. Diese Gruppe ist nicht gleich der Zahl der insgesamt im Ovar vorhandenen Eier, wie das noch Cunningham (1893-95), Fulton (1897) und WheELer (1924) behaupten. Daß die gesamte Eientwicklung sich nicht binnen Jahresfrist vollziehen kann, darauf wiesen schon Calderwood (1891-92), Reibisch (1899), Franz (1910), HickLING (1930) und RaItT (1932) hin auf Grund von Untersuchungen an Scholle, Schellfisch und Seehecht. BoHz (1957) stellt für die Kliesche fest, daß die Reifungsphase länger als ein Jahr dauert. Als erster unternahm MesstorfF (1959) den Versuch, beim Wittling die Zahl der Reserve-Oozyten ungefähr abzuschätzen. Er kommt zu dem Ergebnis, daß sich Reservebestand und reifendes Gelege verhalten wie $4: 1$. Ich habe mich bei den untersuchten Arten bemüht, die Verhältniszahl quantitativ zu ermitteln. Daher sind in den meisten Tabellen außer den für die Fruchtbarkeitsbestimmung maßgeblichen großen Oozyten getrennt die Werte angegeben für alle jüngeren Stadien, die noch nicht heranreifen. Die Ermittlung dieser Zahlen stößt auf erhebliche Schwierigkeiten. Obwohl auch hier der Probenfehler in der 5\%-Schranke gehalten worden ist, kann man den Gesamtfehler von vornherein als höher annehmen, da nicht sicher ist, ob jeweils alle kleinen und kleinsten Oozyten quantitativ erfaßt werden konnten. Sieht man aber von der quantitativen Ungenauigkeit ab, so ist deutlich, daß stets ein Mehrfaches an Reserve-Oozyten vorhanden ist. Die Größe der Verhältniszahl ist artbedingt verschieden. Sie beträgt meist 
ungefähr 5:1. Das bedeutet, daß die Entwicklung einer jungen Oozyte nicht innerhalb eines Jahres erfolgt, sondern sich je nach der Art über einen längeren Zeitraum erstreckt. Es scheint so, als ob sich der Prozentsatz der ReserveOozyten mit zunehmendem Alter des Fisches etwas erhöht. Manchmal bleibt die Geschwindigkeit der oogonialen Teilungen zurück hinter dem Verbrauch. Dann sinkt die Verhältniszahl rapide ab bis auf den Wert von $1: 1$.

\section{Die Regulation der Gelegegröße}

Aus dem bisher Gesagten geht hervor, daß abgestimmte Beziehungen bestehen zwischen dem augenblicklichen Zustand eines Fisches und seiner Eizahl.

In charakteristischer Weise reift ein bestimmter Prozentsatz an Oozyten zum Gelege heran. Welche Faktoren diesen Vorgang steuern, ist uns nicht bekannt. Aus den Untersuchungen von Peters (1957) an dem Buntbarsch Hemichromis bimaculatus geht hervor, daß bei einer experimentellen Entfernung eines Teiles der heranwachsenden Eier die Reserve-Oozyten das Fehlende ersetzen. Auf diese Weise entsteht wieder ein normales Gelege.

Die Gonade hat also grundsätzlich die Fähigkeit Verluste auszugleichen. Sie "weiß", wenn das Verhältnis Reserve-Eier zu reifenden Eiern nicht stimmt. Vielleicht wird der Ausgleich auf Grund stofflicher Spannungsverhältnisse im Ovar herbeigeführt, die in einem bestimmten Stadium nur ein bestimmtes Verhältnis der Oozyten verschiedener Entwicklungsphasen zulassen.

Es ist interessant, daß sich die Zusammensetzung des Blutes in Abhängigkeit vom Laichrhythmus ständig ändert. Der Hämoglobingehalt im Blut des Murmansker Herings schwankt zwischen 42,9 und $65,5 \%$, wobei für jedes Reifestadium ein bestimmter Prozentsatz charakteristisch ist (Naumow 1956). Den höchsten Gehalt an Hämoglobin $(65,5 \%)$ und an Lymphozyten $(87,5 \%$ ) findet man im Oktober und November, kurz vor dem Laichen. Im Mai bis Juni sind die Mengen wesentlich geringer (Hämoglobin 53,4\%, Lymphozyten $37,2 \%$ ), dafür wachsen die Anteile der Monozyten von 8 auf $44 \%$, der Leukozyten von 4,5 auf $19 \%$.

Nach Pawlow und Krolik (1936, zitiert nach Naumow 1956) ist es möglich, auf Grund des Hämoglobingehaltes das Geschlecht unreifer Karpfen zu bestimmen. Das weist wiederum auf die Beziehung zwischen Blut und Ovar hin. Man kann also wohl mit Recht annehmen, daß auch bei marinen Teleosteern die Regulation der Gelegegröße eng zusammenhängt mit der Zusammensetzung des Blutes. Die steuernden Faktoren — wahrscheinlich hormonaler Natur (vergleiche Corpus luteum-Bildung) - sind unbekannt.

E. Die artspezifischen Beziehungen zwischen Eigröße und Größe der Ölkugel

Sehr viele Fischeier verfügen für die Zeit ihrer Entwicklung und die ersten Stadien des Larvenlebens über einen OOlvorrat. Dieser kann in sehr verschiedener Form vorliegen: entweder in einer einzigen Olkugel oder aber in Gestalt mehrerer bis vieler Kugeln verschiedener Größen. Bei einigen Fischarten kommt es während der Entwicklung zu einer Verschmelzung zu einem Tröpfchen. 
$\mathrm{Da}$ die Olkugeln während des Aufbaues von Embryo und Larve verbraucht werden, dienen sie in erster Linie wohl der Ernährung. Es muß angenommen werden, daß die Menge des Olvorrates ziemlich genau für jede Art festgelegt ist. Einmal nämlich wird jedes Ei nur soviel mitbekommen, wie für die Ernährung unbedingt notwendig ist. Ein Zuviel würde den Stoffhaushalt des Mutterfisches unnötig hoch beanspruchen. Zum anderen wird, vor allem für planktische Eier, das hydrostatische Gleichgewicht eine Rolle spielen. Um das $\mathrm{Ei}$ in schwebendem Zustand zu halten, muß es notwendigerweise etwa das spezifische Gewicht des umgebenden Mediums haben, also des Süß- oder Salzwassers verschiedener Konzentration. Die Lage der Olkugel in Ei und Larve ist genau festgelegt.

Für eine Untersuchung dieses Problems bieten sich die Eier an, die nur eine Ölkugel enthalten, weil die Lösung bei ihnen am einfachsten erscheint. Ergibt sich eine Gesetzmäßigkeit der Größenverhältnisse, so kann man aus den oben erwähnten Gründen wohl ohne weiteres eine solche auch annehmen für Eier ohne Ol (die ihren Fettvorrat in anderer Form enthalten) und Eier mit mehreren oder vielen Olkugeln.

In der Bestimmungsliteratur für Fischeier (Heincke und Ehrenbaum 1900) werden Eidurchmesser, Größe und Farbe der Olkugeln schon seit langem als wichtige Kriterien benutzt, ohne daß aber ihre Beziehungen bisher näher analysiert worden wären.

Auf Abb. 37 ist der Durchmesser der Olkugel gegen den Eidurchmesser aufgetragen. Jede Kurve gibt die Werte für eine Art wieder. Dabei entspricht der mittlere Punkt durchschnittlichen Maßen, die beiden äußeren geben die Extremwerte wieder. Da die Größen der Fischeier variieren, ist die ideale Darstellungsmöglichkeit der Beziehungen durch einen Punkt nicht gegeben. Aber auch die Kurvenschar zeigt das Wesentliche: alle Kurven gruppieren sich um eine Gerade, die den Anstieg 1:5 hat. Besonders erwähnen möchte ich noch, daß sich auch die Eier von Anarrhichas lupus L., die ich ihrer Größe wegen nicht eingetragen habe, gut in das Gesamtbild einfügen. Die der graphischen Darstellung zugrunde liegenden Werte sind der Tabelle 12 zu entnehmen. In der letzten Spalte habe ich aus den Mittelwerten von Eidurchmesser $\left(D_{m}\right)$ und Olkugeldurchmesser $\left(d_{m}\right)$ den Quotienten $(Q)$ gebildet und das Mittel der Quotienten als Anstieg der Geraden berechnet.

Eine Art fällt aus der Kurvenschar besonders heraus: Sardina pilchardus. Bei der Sardine handelt es sich um eine ursprünglich mediterran-atlantische Art. Es ist anzunehmen, daß ihre Eier auf die Salzkonzentration dieser Meere abgestimmt waren. Mit der Ausbreitung des Laichgebietes über den Kanal in die Nordsee wurde eine Anpassung an die veränderten Konzentrationen durch eine Vergrößerung des perivitellinen Raumes notwendig. Statistisch verwertbare Angaben über die Beziehungen zwischen Eidurchmesser und Größe der Olkugel in den verschiedenen Laichgebieten waren nicht zu erhalten. Von anderen Arten ist aber der Einfluß des Salzgehaltes auf die Größe von Ei und perivitellinem Raum bekannt. An den Eiern von Engraulis encrasicholus L. wurde beobachtet, daß sie im Brackwasser größer sind als im Salzwasser. Die Eier von Sprattus sprattus (L.) besitzen normalerweise keinen perivitellinen Raum. In der östlichen Ostsee bilden sie dagegen nach Veröffentlichungen von ScHNeider (1901) einen solchen aus.

Abschließend möchte ich darauf hinweisen, daß die Abb. 37 eine Hilfe bei der schnellen Identifizierung von Fischeiern bilden kann. Man wird wie üblich zuerst die Eier mit einer Olkugel heraussortieren und sie dann ausmessen. Die dem Schnittpunkt der Meßwerte in der 


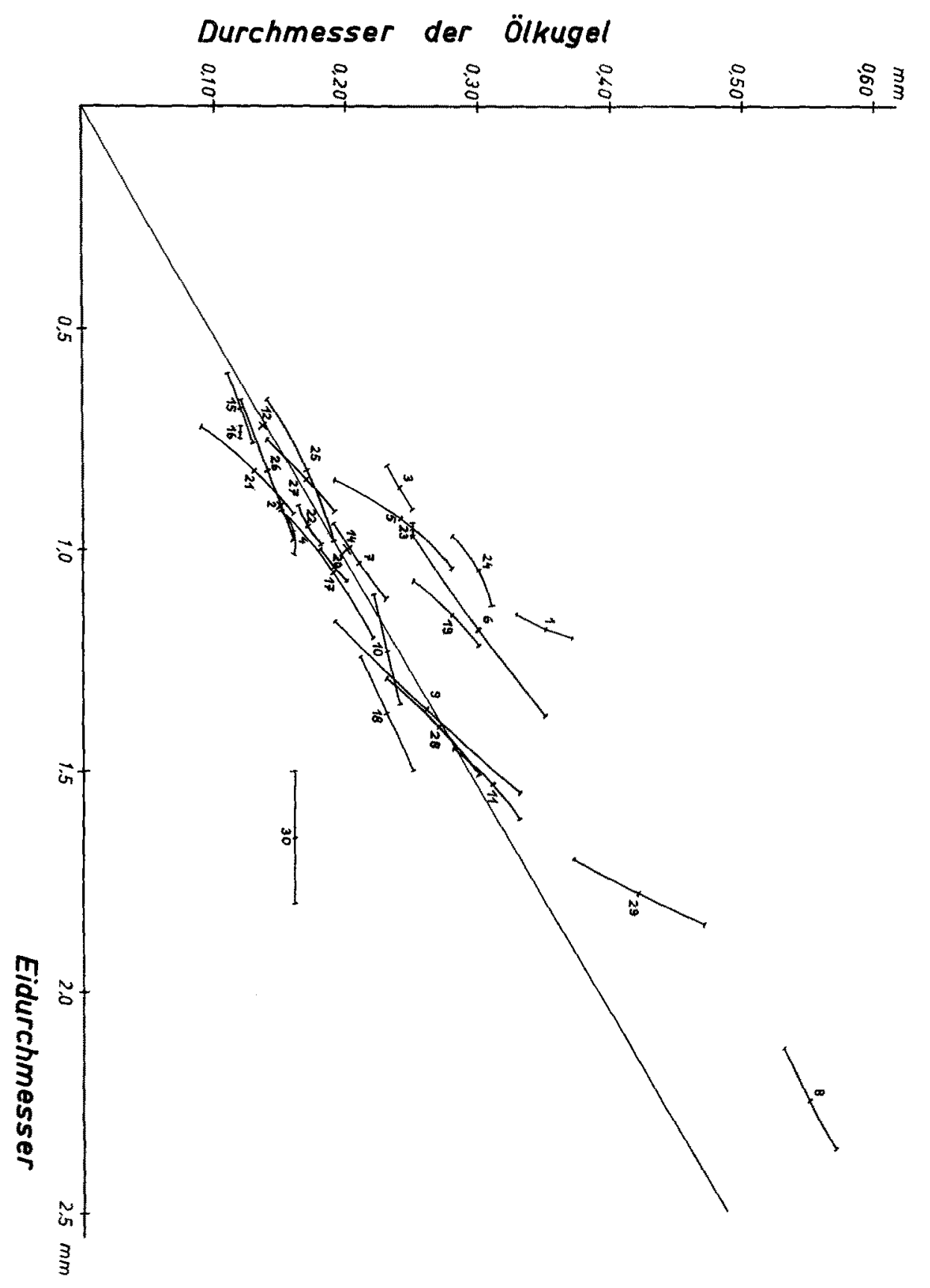

Abb. 37: Zusammenhang zwischen Eidurchmesser und Durdmesser der Olkugel

Tafel am nächsten liegende Kurve gibt eine Kennziffer, unter der aus der Tab. 12 die Art abzulesen ist. Berücksiclitigt man die verschiedenen Laichzeiten, so wird es oft möglich sein, unmittelbar zu einem richtigen Ergebnis zu gelangen. Wenigstens wird man das Nachschlagen in der Literatur auf einige wenige Arten beschränken können. 


\begin{tabular}{|c|c|c|c|c|c|c|c|}
\hline \multirow[b]{2}{*}{$\begin{array}{l}\text { Kenn- } \\
\text { Ziffer }\end{array}$} & \multicolumn{3}{|c|}{ Tabelle 12} & \multirow[b]{2}{*}{$\mathrm{D}_{\mathrm{m}}$} & \multirow[b]{2}{*}{ d } & \multirow[b]{2}{*}{$\mathrm{d}_{\mathbf{m}}$} & \multirow[b]{2}{*}{$Q$} \\
\hline & Art & $\begin{array}{c}\text { Laich- } \\
\text { zeit }\end{array}$ & $\mathrm{D}$ & & & & \\
\hline 1 & Roccus labrax & VII - VIII & $1,15-1,20$ & 1,18 & $0,33 \longrightarrow 0,37$ & 0,35 & 3,37 \\
\hline 2 & Serranus cabrilla & V-VIII & 0,90 & 0.90 & 0,15 & 0,15 & 6,00 \\
\hline 3 & Mullus surmuletus & $\mathrm{V}-\mathrm{VI}$ & $0,81-0,91$ & 0,86 & $0,23-0,25$ & 0,24 & 3,58 \\
\hline 4 & Capros aper & VI-VIII & $0,91-1,01$ & 0,96 & $0,15-0,16$ & 0,16 & 6,00 \\
\hline 5 & Caranx trachurus & $\mathrm{VI}-\mathrm{VIII}$ & $0,84--1,04$ & 0,93 & $0,19-0.28$ & 0,24 & 3,88 \\
\hline 6 & Scomber scombrus & $\mathrm{V}-\mathrm{VIII}$ & $0,97-1,38$ & 1,18 & $0,25-0,35$ & 0,30 & 3,93 \\
\hline 7 & Trachinus draco & VI-VIII & $0,94-1,11$ & 1.03 & $0,19-0,23$ & 0,21 & 4,90 \\
\hline 8 & Lophius piscatorius & VI-VIII & $2,13-2,36$ & 2.25 & $0,53-0,57$ & 0,55 & 4,09 \\
\hline 9 & Trigla gurnardas & IV-VIII & $1,16-1,55$ & 1,36 & $0,19-0,33$ & 0,26 & 5,23 \\
\hline 10 & Trigla hirundo & IV $-\mathrm{X}$ & $1,10-1,35$ & 1,23 & $0,22-0,24$ & 0.23 & 5,35 \\
\hline 11 & Trigla pini & $I V-V I$ & $1,45-1,61$ & 1,53 & $0,28-0,33$ & 0,31 & 4,94 \\
\hline 12 & Cepola rubescens & VI & 0,72 & 0,72 & 0,135 & 0,14 & 5.33 \\
\hline 13 & Anarrhichas lupus & $\mathrm{XI}-\mathrm{I}$ & $5,50-6,00$ & 5.75 & 1,75 & 1,75 & 3,29 \\
\hline 14 & Mugil capito & $\mathrm{V}-\mathrm{VI}$ & 1,00 & 1,00 & 0,20 & 0,20 & 5,00 \\
\hline 15 & Platophrys laterna & VI-VIII & $0,60-0,76$ & 0,68 & $0,11-0,13$ & 0,12 & 5,67 \\
\hline 16 & Platophrys grohmanni & $\mathrm{VI}-\mathrm{VII}$ & $0,72-0,74$ & 0,73 & 0,12 & 0,12 & 6.08 \\
\hline 17 & Scophthalmus maximus & IV-VIII & $0,91-1,20$ & 1,05 & $0,15-0,22$ & 0,19 & 5,55 \\
\hline 18 & Scophthalmus rhombus & $\mathrm{V}-\mathrm{VIII}$ & $1,24-1,50$ & 1,37 & $0,21-0,25$ & 0,23 & 5,96 \\
\hline 19 & Lepidorhombus whiff & III $-\mathrm{V}$ & $1,07-1,22$ & 1,15 & $0,25-0,30$ & 0,28 & 4,11 \\
\hline 20 & Zeugopterus punctatus & IV-VI & $1,00-1,07$ & 1,04 & $0,18-0,20$ & 0,19 & 5,47 \\
\hline 21 & Scophthalmus norvegicus & IV-VIII & $0,72-0,92$ & 0,82 & $0,09-0,16$ & 0,13 & 6,51 \\
\hline 22 & Scophthalmus unimaculatus & $I V-V I$ & $0,90-0,99$ & 0,95 & $0,16-0,18$ & 0,17 & 5,59 \\
\hline 23 & Merluccius merluccius & VII-VIII & $0,94-0,97$ & 0,96 & 0,25 & 0,25 & 3,84 \\
\hline 24 & Molva molva & $\mathrm{III}-\mathrm{VI}$ & $0,97-1,13$ & 1,05 & $0,28-0,31$ & 0,30 & 3,50 \\
\hline 25 & Enchelyopus cimbrius & II-VIII & $0,66-0,98$ & 0,82 & $0,14-0,19$ & 0,17 & 4,82 \\
\hline 26 & Onos mustela & $\mathrm{I}-\mathrm{VI}$ & $0,66-0,98$ & 0,82 & $0,12-0,16$ & 0,14 & 5,86 \\
\hline 27 & Raniceps raninus & $V-I X$ & $0,75-0,91$ & 0,84 & $0,14-0,19$ & 0,17 & 4,94 \\
\hline 28 & Brosmius brosme & $\mathrm{IV}-\mathrm{VI}$ & $1,29-1,51$ & 1,40 & $0,23-0,30$ & 0,27 & 5,19 \\
\hline 29 & Argentina sphyraena & $\mathrm{III}-\mathrm{V}$ & $1,70-1,85$ & 1,78 & $0,37-0,47$ & 0,42 & 4,24 \\
\hline 30 & Sardina pilchardus & VI-VIII & $1,50-1,80$ & 1.65 & 0,16 & 0,16 & 10,31 \\
\hline
\end{tabular}

\section{Zusammenfassung}

Die Ovarien von zehn Arten mariner Teleosteer werden untersucht durch methodische Verbindung von quantitativer Zählung und histologischer Bearbeitung.

Das Grundschema des Ovarbaues umfaßt fünf Bestandteile, deren Anordnung nicht immer einheitlich ist: Bindegewebe, Pigmentschicht, Ring- und Längsmuskulatur und Keimepithel.

Aus den Oogonien entstehen die Oozyten I. Ordnung. Sie bilden einen Reservebestand, aus dem sich alljährlich eine Gruppe von etwa $20 \%$ herauslöst und zu einem Gelege heranwächst. Die Entwicklung der Oozyten läßt sich in vier zytologische Stadien einteilen. Der zunächst zentral gelegene Kern verläßt im Stadium IV die Zellmitte. Durch Auswanderung von Kernsubstanz wird dem Plasma die enorme Dotterbildung ermöglicht.

Die Chromosomen sind bis zum Ende der 1. Wachstumsphase sichtbar. Während dieser Zeit erfolgt die Vorbereitung der 1. Reifungsteilung. Während der 2. Wachstumsphase ist DNS nicht nachzuweisen. Sie taucht erst kurz vor den Reifungsteilungen wieder auf.

Eine Zona radiata im Sinne der Definition gibt es bei den untersuchten Teleosteern nicht. Es treten aber ähnliche Strukturen auf: das Stratum radia- 
tum als vorübergehende Bildung im Plasma und die Cortex radiata in den Hüllschichten.

Der Aufbau der Eihülle erfolgt von innen her, nicht vom Follikel.

Die Begriffe "kurze Laichzeit" - "lange Laichzeit" werden gegeneinander abgegrenzt.

Nach der Art der Oozytenreifung sind folgende Fischtypen zu unterscheiden:

1. Diskontinuitätstyp: Die reifenden Oozyten lösen sich völlig vom Reservebestand. Der Laichvorgang erfolgt binnen kurzer Zeit. Hierher gehören Fische mit nördlichem Verbreitungsgebiet, dic bei uns am Anfang des Jahres laichen.

2. Kontinuitätstyp: $Z$ wischen reifenden und Reserve-Oozyten finden sich histologisch und größenmäßig Ubergänge. Die Oozyten reifen in Schüben. Dadurch erstreckt sich der Laichvorgang über einen längeren Zeitraum. $\mathrm{Zu}$ dieser Gruppe sind Fische mit vorwiegend südlichem Verbreitungsgebiet zu rechnen, die bei uns im Sommer laichen.

Zwischen diesen beiden Gruppen vermittelt eine dritte, zu der Fische gehören, die wenigstens zweimal im Jahr Eier legen.

Für die Bestimmung der Fruchtbarkeit dürfen von einem bestimmten Zeitpunkt an nur Oozyten über einer gewissen Größe benutzt werden. Zeitpunkt und Grenzgröße werden für die untersuchten Arten angegeben.

Die in vielen planktischen Eiern vorhandenen Olkugeln haben etwa $1 / 5$ des Eidurchmessers. Die genauen Größenbeziehungen sind artspezifisch verschieden und können für die Identifizierung benutzt werden.

\section{Summary}

The ovaries of ten species of marine teleosteans are investigated by methodically combining quantitative counts and histological treatment.

The principal scheme of the ovary structure comprises five parts the arrangement of which is not always the same: Connective tissue, pigmentary layer, ring and longitudinal musculature, and germinal epithelium.

The oogonia develop into oocytes of the ist order representing a reserve stock from which a group of about $20 \%$ emerges annually to grow into an egg deposit. The development of the oocytes may be divided into four cytological stages. The nucleus, situated centrally at first, leaves the cell center at stage 4 . The extrusion of nuclear substances enables the cytoplasma to accumulate the enormous quantity of yolk.

The chromosomes are visible until the end of the first growth phase. During this time the first maturation division is initiated. During the second growth phase DNA cannot be found. It reappears only shortly before the maturation divisions.

There is, to definition, no 'zona radiata' to be found in the teleosteans investigated, though similar structures do appear: the "stratum radiatum' as a passing formation in the cytoplasma and the 'cortex radiata' in the integument layers.

The egg integument is built up from the interior, and not from the follicle.

The conceptions "short spawning period" - 'long spawning period" are specified distinctly. 
The following types of fish are to be distinguished according to the kind of oocyte maturation:

1. Discontinuity type: the maturing oocytes are released completely from the reserve stock. The process of spawning takes place within a short time. This includes fishes of a northern distribution range which, in our region, do spawn in the beginning of the year.

2. Continuity type: there are histological and dimensional transitions to be found between maturing and reserve stock oocytes. The oocytes mature at intervals. Thus the spawning process does extend over a longer period. This group includes fishes of a preferably southern distribution range; in our region spawning takes place in summer.

Between these two groups there is an intermediate one comprising fishes that produce eggs at least twice a year.

After a certain period fertility can be determined only by using oocytes that have reached a certain size. Time and size limits are given for species investigated.

The oil globules occurring in many planktonic eggs are of about $1 / 5$ th of the egg diameter. The exact relations of size are specifically different and may be used for identification.

\section{Angeführte Schriften}

A mbros, A. I.: Die Heringe der Peter-I-Bucht. Pinro Abh. 6, Wladiwostok (1931), russ. A n ke l, W. E.: Ei und Eibildung. Handwörterb. Naturwiss, 3, 7 (1933)

Arndt, E. A.: Histologische und histochemische Untersuchungen über die Oogenese und bipolare Differenzierung von Süßwasser-Teleosteern. Protoplasma 47, 1-36 (1956)

- Untersuchungen über die Eihüllen von Cypriniden. Z. Zellforsch. 52, 3, 315-327 (1960)

A urich. H. J.: Causes of the changes in the stocks of some summer spawners, in the southern North Sea - a working hypothesis. Internat. Commiss. Northwest Atlantic Fish. 1 (1958)

B arfurt, D.: Biologische Untersuchungen über die Bachforelle. Arch. mikr. Anat. 27 (1886)

B ě 1 a r̆, K.: Die cytologischen Grundlagen der Vererbung. Handb. Vererbungswiss., Berlin (1928)

B e rt i n, L.: Sexualité et fécondation. in: Grassé, Traité de Zoologie, 13, 2 (1958)

B o h l, H.: Die Biologie der Kliesche (Limanda limanda L.) in der Nordsee. Ber. Dtsch. wiss. Komm. Meeresforsch. 15, 1, I-57 (1957)

B ra che t, J.: Ribonucleic acids and the synthesis of cellular proteins. Nature 186, 194-199 $(1960)$

Bretschneider, L. H., u. Duyvené de Wit, J. J.: Über die Hormonkette: Wirk. same Harnsubstanz $\rightarrow$ Ovar $\rightarrow$ Legeröhre bei Rhodeus amarus; bewiesen durch die histologische Stufenzählmethode. Proc. 40, 7, 624 ff. (1937)

- Sexual Endocrinology of Non-Mammalian Vertebrates. Elsevier (New York), 146 ff. (1947)

B ü ckm a nn, A.: Die Methodik fischereibiologischer Untersuchungen an Meeresfischen. in: Handb. biol. Arbeitsmethod., Abt. IX, Teil 6 (1938)

Calderwood, W. L.: A contribution to our knowledge of the ovary and intra-ovarian eggs in teleosteans. J. marin. biol. Ass., N. S., 2 (1891-92)

$\mathrm{Ch}$ a udhry, H. S.: The origin and structure of the zona pellucida in the ovarian eggs of Teleosts. Z. Zellforsch. 43, 478-485 (1956)

Cun $\mathrm{n}$ in $\mathrm{gh}$ a m, J. T.: The ovaries of fishes. J. marin. biol. Ass., N. S. 3 (1893-95)

- On the histology of the ovary and of the ovarian ova in certain marine fishes. Quart. J. micr. Sci., N. S. $40(1898)$

Ehren ba um, E.: Eier und Larven von Fischen der Deutschen Bucht. III. Fische mit festsitzenden Eiern. Wiss. Meeresunters. Helg. 6, 127-200 (1904)

Ek m a n, S.: Tiergeographie des Meeres. Akad. Verl. Ges. (Leipzig), 542 S. (1935) 
Franz, V.: Die Eiproduktion der Scholle. Wiss. Meeresunters. Helg., N. F. 9 (1910)

Fult on, F.: On the growth and maturation of the ovarian eggs of teleostean fishes. Rep. Fish. Bd. Scotland 16 (1897)

Glebow, T. I.: Die Küstenwanderungen des Murmansker Herings im Zusammenhang mit ökologischen Faktoren. Prnro Abh. 1 (1938), russ.

Hann. H. W.: The history of the germ-cells of Cottus bairdii. J. Morph. Physiol. 43, $497 \mathrm{ff} .(1927)$

Heincke, Fr.: Naturgeschichte des Herings. Abh. Dtsch. Seefischereivereins 1, 1 (1897)

Heincke, Fr., u. Ehrenbaum, E.: Eier und Larven von Fischen der Deutschen Bucht. Wiss. Meeresunters. Helg., N. F. 3 (1900)

Hickling, G. F.: Seasonal changes in the condition of the hake. Fish. Invest., Ser. II, 12, 1 (1930)

Hickling, C. F., u. R u $t$ enberg, E.: The ovary as an indicator of the spawning period in fishes. J. marin. biol. Ass. 21 (1936)

$\mathrm{J}$ on $\mathrm{g}, \mathrm{J}$. K. de: A preliminary investigation on the spawning habits of some fishes of the Java Sea. Treubia $17(1940)$

$K$ ändler, R., u. Pirwitz, W.: Uher die Fruchtbarkeit der Plattfische im NordseeOstsee-Raum. Kiel. Meeresforsch. 13, 1 (1957)

K is selewitsch. K. A.: Materials on the biology of the Caspian herrings. I. The fertility of the Wolga-Caspian herrings. Rep. Ichthyol. Lab. Astrachan 5 (1923)

Krause, R.: Mikroskopische Anatomie der Wirbeltiere in Einzeldarstellungen. Gruyter \& Co. (Berlin-Leipzig), 677 ff. (1921)

L or en zen, H.: Ribonucleinsäure und die Proteinsynthese in der Zelle. Naturw. Rdsch. 13, 273 (1960)

$\mathrm{Ma}$ i e r. H. N.: Beiträge zur Altersbestimmung der Fische. I. Allgemeines. Die Altersbestimmung nach den Otolithen bei Scholle und Kabeljau. Wiss. Meeresunters., N. F. 8, Abt. Helg., 1 (1908)

Messtorff, J.: Untersuchungen über die Biologie des Wittlings Merlangius merlangus (L.) in der Nordsee. Ber. Dtsch. wiss. Kornm. Meeresforsch. 15, 4, 277--334 (1959)

$\mathrm{Na}$ u mow, W. M.: Oogenese and Okologie des Geschlechtszyklus des Murmansker Herings (Clupea harengus harengus L.). Veröff. Forsch. Inst. Seefischereiwirtsch. Oceanographie Knipowitsch 9 (1956), russ.

Orto n, J. H.: Sea temperature, breeding and distribution of marine animals. J. marin. biol. Ass. 12, 339-366 (1920)

Peters, H. M.: Über die Regulation der Gelegegröße bei Fischen. Z. Naturforsch. $12 \mathbf{b .}$ $255-261(1957)$

Petrowa, W. G.: Zytodhemische Untersuchungen der Eizellen der Fische. Doklad. Akad. Nauk SSSR 110, 4, 674-676 (1956), russ.

Quasim, S. Z.: Time and duration of the spawning season in some marine teleosts in relation to their distribution. J. Conseil int. Expl. Mer 21, 2, 144-155 (1956)

$\mathrm{R}$ a it $t$, D. S.: The fecundity of the haddod. Fish. Board Scot., Sci. Invest. 1, 1-42 (1933)

R a u the r. M.: Echte Fische. In: Bronn, K1. Ord. 6, Abt. 1, 2, II, 2 (1954)

R e i b is $\mathrm{ch}$, J.: Uber die Eizahl bei Pleuronectes platessa und die Altersbestimmung dieser Form an den Otolithen. Wiss. Meeresunters. Kiel, N. F, 4, 233-248 (1899)

Retzius, M. G.: Zur Kenntnis der Hüllen und besonders des Follikelepithels an den Eiern der Wirbeltiere. I. Bei den Fischen. Biol. Unters, N. S. 17, 5-29 (1912).

Schnakenbeck. W.: Heterosomata. in: Tierwelt der Nord- und Ostsee, 6 (1996).

Schneider, G.: Uber die Fortpllanzung von Clupea sprattus L. im Finnischen Meerbusen. Zool. Anz. 25, 659, 9-11 (1901).

$\mathrm{Schrader}$, F.: The extrusion of desoxyribose nucleic acid from the nucleus in the formation of nutritive materials in the $\mathrm{egg}$. Science 114, 486 (1951).

Schtrajch, G., und Swetosarow, E.: Die Bedeutung der Außenfaktoren im Sexualzyklus der Kaltblüter. Doklad. Akad. Nauk SSSR 29, 8/9 (1940), russ.

Semmens, C. J., und Bhaduri, P. N.: Staining the nucleolus. Stain Technol. 16. $119-120(1941)$.

Shelford, V. E., und Powers. E. B.: An experimental study on the movement of herring and other marine fishes. Biol. Bull. Mar. Biol. Lab. 29 (1915).

Smirnow, A. I.: Das portionsweise Laichen der pelagophilen Fische des Schwarzen Meeres. Doklad. Akad. Nauk SSSR 70 (1950), xuss.

S te rba, G.: Zur Differenzierung der Eihüllen bei Knochenfischen. Z. Zellforsch. 46, 717798 (1957). 
S te rba, G., und Franke, H.: Zur elektronenmikroskopischen Struktur der Corticalmembran der Knochenfischeier. Naturw. 46, 93 (1959).

S töh r, P.: Lehrbuch der Histologie. Fischer (Jena), 516 S. (1919).

Takeshita, K., und Aikawa, H.: Biology of Japanese Anchovy, Engraulis japonica, in the Nankai Region. Rec, Oceanogr. Work Japan, Spec. Nr. 4 (1960).

Tomasi, J. A. de: Improving the technic of the Feulgen stain. Stain Technol. 11, 143 (1936).

Wess ing, A.: Beobachtungen über den Austritt von Chromatin ins Plasma bei der Keimzellenreifung eines Nematoden. Naturw. 41, 95 (1954).

Whe eler, I. F. G.: The growth of the egg in the dab. Quart. J. micr. Sci. 68 (1924).

Wickler, W.: Das Ei von Blennius fuviatilis Asso ( $=$ Bl. vulgaris). Z. Zellforsch. 45, $641-648(1957)$. 